\title{
El CONCEPTO DE PAZ EN LA CONSTITUCIÓN Política de Colombia de 1991: RECONSTRUCCIÓN DIALÉCTICA DE SU SIGNIFICADO A PARTIR DE LA JURISPRUDENCIA DE LA CORTE CONSTITUCIONAL*
}

\section{FrANKLIN MORENO MILLÁN**}

Resumen: El concepto de Paz en la Constitución Política de Colombia de 1991 es polivalente. Según la jurisprudencia constitucional en Colombia, puede asumir diversas expresiones según sean los sujetos involucrados, las situaciones en conflicto y los mecanismos para solucionarlos. Evaluar estos conceptos permite un acercamiento dogmático a lo que la Constitución Política de 1991 quiere y, por ende, lo que las autoridades y los particulares deben hacer en relación con este concepto. Para tal fin, se recurre a algunos de los criterios que permiten acercarse al peso abstracto de los principios en el principio de proporcionalidad. Este ejercicio mostrará una mayor eficacia o un mayor peso de algunos conceptos respecto de los otros.

PALABRAS CLAVE: Paz - Conflicto - Guerra - Negociación - Principio.

\section{THE CONCEPT OF PEACE IN THE 1991 \\ Political Constitution of Colombia: \\ DIALECTIC RECONSTRUCTION OF ITS MEANING FROM JURISPRUDENCE OF THE CONSTITUTIONAL COURT}

ABSTRACT: The concept of Peace in the 1991 Political Constitution of Colombia is versatile. According to constitutional jurisprudence in Colombia, it can assume different expressions depending on the subjects

Este estudio se enmarca en el proyecto "Politica, Derecho y Posconflicto: Transformaciones Institucionales en Colombia", proyecto de investigación que inicia en el primer semestre del año 2014 y que es financiado por la Universidad de San Buenaventura Cali. Fecha de inicio abril de 2014.

Fecha de recepción: 27 de mayo de 2014.

Fecha de aceptación: 1 de julio de 2014.

** Abogado (2002), Magíster en derecho - énfasis en derecho público (2007). Actualmente adelantando cursos independientes de doctorado con la Universidad de Buenos Aires (ARgentina). Profesor de Tiempo Completo Asociado, Universidad de San Buenaventura, Cali (Colombia). Correo electrónico: fjmoreno@usbcali.edu.co 
involved, conflicting situations and mechanisms to solve them. To evaluate these concepts allows a dogmatic approach to what the 1991 Constitution wants and thus, what the authorities and individuals must make in connection with this concept. For this purpose, we resort to some of the criteria for weight approach to abstract principles on the principle of proportionality. This exercise will show greater efficacy or greater weight of some concepts regarding the other.

KEY WORDS: Peace - conflict - war - negotiation - Principle.

Sumario: Introducción. 1) La naturaleza de la Paz. 1.1) La Paz como valor. 1.2) La Paz como principio. 2) Significado de la paz. 2.1) Polivalencia de significados en la Constitución Politica de 1991. 2.1.1.) La Paz como valor o estado ideal pretendido tanto por el derecho interno como por el derecho internacional. 2.1.2.) La Paz como protocolo de actuación en medio de los conflictos. 2.1.3.) La Paz como derecho colectivo. 2.1.4.) La Paz como derecho fundamental o subjetivo. 2.1.5.) La Paz como deber ciudadano o constitucional. 3) Criterios de determinación del peso abstracto de los diferentes conceptos de paz en la CP de 1991. Conclusiones. Bibliografía.

\section{INTRODUCCIÓN}

La Constitución Política de Colombia de 1991, fue el resultado de algunos procesos de negociación con grupos armados al margen de la ley del descontento generalizado de una sociedad que sentía que el marco constitucional vigente estaba lejos de responder a las necesidades sociales.

Conocida como una "Constitución para la Paz", el texto hizo referencia a la Paz en diversos artículos y desde diferentes ópticas. Así, se habló en el Preámbulo de la Paz como valor, en el Artículo 22 de la Paz como derecho fundamental y en el Artículo 95 de la Paz como deber constitucional. A esto se suma que la jurisprudencia de la Corte Constitucional de Colombia asume la Paz desde una polisemia todavía más amplia en la que se incluye la Paz como estado ideal, como principio (tanto desde la perspectiva de derecho fundamental como de derecho colectivo), con lo cual la ausencia de un concepto definitivo lleva a enormes dificultades en la comprensión del concepto y en la reclamación judicial de las garantías que del mismo se podrían desprender.

Las dificultades se incrementan cuando, como ocurre en este momento, estamos en un proceso de negociación con un grupo armado ilegal, se reforma la Constitución Política de 1991 para introducirle un "Marco jurídico para la paz" y se lleva el concepto Paz al lenguaje común como un elemento más de la cotidianidad. 
Tal situación generó la necesidad de adelantar un estudio sobre el significado dogmático del concepto Paz en la Constitución Política de Colombia de 1991, especial pero no únicamente desde la jurisprudencia de la Corte Constitucional de Colombia.

Señalamos que especial pero no únicamente porque, partiendo de los fundamentos teóricos que subyacen a los deferentes pronunciamientos judiciales, se pretende un acercamiento con unos elementos medulares que sirvan de consenso cuando el concepto se utilice.

Para tal fin, el presente estudio parte del análisis de la actividad de la Corte Constitucional de Colombia al respeto, por lo que el modelo es el de la investigación jurisprudencial ${ }^{1}$, el cual busca evidenciar los cambios dogmáticos que se han producido en el ámbito de la jurisprudencia. La investigación -con alcance descriptivo- se hace desde el enfoque cualitativo, en tanto parte del análisis de conceptos (posiciones jurisprudenciales), los cuales se interpretan y se presentan en un informe con los resultados sistematizados. El método es hermenéutico por cuanto el objeto propuesto corresponde a la comprensión de un fenómeno jurídico: la Paz. Como lo afirmara Gadamer ${ }^{2}$, entrańa no solo el acto de conocer o reconocer el sentido, sino la apropiación de este.

Vale la pena comentar que, en el caso colombiano, no existen estudios sobre el alcance de la Paz en la Constitución Política de 1991 y, por ende, también se carece de estudios sobre la lectura que la Corte Constitucional ha hecho de este concepto. De allí que el análisis se centra en la comprensión de la jurisprudencia y los fundamentos teóricos, sean todos de derecho comparado.

\section{1) La naturaleza de la paz}

Desde una perspectiva constitucional, la $\operatorname{Paz}$ (a la cual aludiremos como sustantivo), tiene la doble condición de valor y de principio. Como valor, representa uno de los fines más preciados del ordenamiento. Como principio, no solo es pauta de interpretación y creación de normas, sino que puede incluso ser objeto de aplicación directa en casos concretos ${ }^{3}$.

1 Latorre Latorre, Virgilio (2012) Bases metodológicas de la investigación jurídica. Valencia: Tirant lo Blanch, 199 pp. 149-166

2 Gadamer, Hans-Georg (1998) Verdad y método. Tomo II. 3a edición. Traducción de Manuel Olasagasti. Salamanca: Ediciones Sígueme, 429 pp., p. 95.

3 Sobre las funciones interpretativa, creativa e integradora de los principios ver VALENCIA Restrepo, Hernán (1999) Nomoárquica, principialistica jurídica o de los principios generales del derecho. Bogotá: Temis, 530 pp. Además, Corte Constitucional. 5 de junio de 1992. "Proceso de acción de tutela promovido por el señor José Manuel Rodríguez Rangel contra el señor Enrique Chartuny González, gerente de las Empresas Públicas de Carta- 
Esta teorización acerca de la Paz no es una cosa vana. Como afirma López ${ }^{4}$, puede ser un problema más de orden práctico que teórico, pero ello, por sí mismo, no descarta la construcción de "una rigurosa teoría de la paz", siendo una causa del fracaso del voluntarismo de la Paz la ausencia de una idea clara de lo que esta es y de lo que persigue. De allí la preocupación de acercarnos al concepto de Paz en la Constitución Política de Colombia de 1991 a partir de la jurisprudencia de la Corte Constitucional toda vez que, si en las fuentes constitucionales del derecho en Colombia la jurisprudencia, bajo ciertas condiciones es vinculante, el concepto de Paz que en ella se maneje también lo es ${ }^{5}$.

\section{1) LA PAZ COMO VALOR}

Toda Constitución Política contiene una dimensión axiológica que sirve de enjuiciamiento del ordenamiento jurídico y de impulso de ciertos comportamientos ${ }^{6}$. Entre los valores más recurrentes se encuentran el bienestar general, la justicia y la Paz. Esta idea de la Paz como valor la encontramos desde Hobbes ${ }^{7}$ para quien existen pasiones que inclinan naturalmente al hombre hacia la Paz. Dichas pasiones se encuentran go-

gena”. Sentencia T-406 de 1992. Disponible en http:/www.corteconstitucional.gov.co/ relatoria/1992/T-406-92.htm [Fecha de visita 14 de mayo de 2014], pp. 11-12.

4 López Calera, Nicolás María (1993). "Vivir en Paz: Paz y derechos humanos". Derechos y libertades. Revista del Instituto Bartolomé de las Casas. Año No. 1, No 1, pp. 169-178.

5 Sobre el valor de la jurisprudencia en las fuentes del derecho en Colombia véase López MeDina, Diego Eduardo (2007) El derecho de los jueces. 2a ed. Bogotá: Legis, 366 pp. Moreno Millán, Franklin (2002) La jurisprudencia constitucional como fuente del derecho. Bogotá: Leyer, 191 pp. En la jurisprudencia constitucional véase, especialmente, CorTe ConstituCIONAL. 9 de agosto de 2001. "Demanda de inconstitucionalidad contra el artículo $4^{\circ}$ de la ley 169 de 1.896”. Sentencia C-836 de 2001. Disponible en http://www.corteconstitucional. gov.co/relatoria/2001/C-836-01.htm [Fecha de visita 14 de mayo de 2014] p. 19-38; Corte Constitucional. 24 de agosto de 2011. "Demanda de inconstitucionalidad contra el artículo 10 (parcial) de la Ley 1437 de 2011 "por la cual se expide el Código de Procedimiento Administrativo y de lo Contencioso Administrativo". Sentencia C-634 de 2011. Disponible en http://www.corteconstitucional.gov.co/relatoria/2011/C-634-11.htm [Fecha de visita 14 de mayo de 2014] pp. 28-43; Corte Constitucional. 1 de noviembre de 2011. "Demanda de inconstitucionalidad: del artículo 102 (parcial) de la Ley 1437 de 2011, por la cual se expide el Código de Procedimiento Administrativo y de lo Contencioso Administrativo". Sentencia C-816 de 2011. Disponible en http://www.corteconstitucional.gov.co/relatoria/2011/C-816-11. htm [Fecha de visita 14 de mayo de 2014] pp. 29-35; Corte Constitucional. 25 de julio de 2012. "Demanda de inconstitucionalidad: de los artículos 102 (parcial), 269 (parcial) y 270 (parcial) de la ley 1437 de 2010 "Por la cual se expide el Código de Procedimiento Administrativo y de lo Contencioso Administrativo del artículo 102 (parcial) de la Ley 1437 de 2010, por la cual se expide el Código de Procedimiento Administrativo y de lo Contencioso Administrativo". Sentencia C-588 de 2012. Disponible en http://www.corteconstitucional.gov.co/ relatoria/2012/C-588-12.htm [Fecha de visita 14 de mayo de 2014] pp. 7-20.

6 Sagües, Néstor (2007) Manual de derecho constitucional. Buenos Aires: Editorial Astrea de Alfredo y Ricardo Depalma. 957 pp., p. 47.

7 Hоввеs, Thomas (1993) "Leviathan". In Great Books of the Western World. No. 21. Chicago: Encyclopaedia Britannica, inc. 43-283 pp., p. 84 and s.s. 
bernadas por unas leyes naturales “inmutables y eternas" que se pueden descubrir a través de la razón. Las tres reglas formuladas por Hobbes se pueden resumir así: i) la Paz debe buscarse y seguirse, incluso, usando las ventajas de la guerra; ii) los hombres deben estar dispuestos a renunciar a sus derechos en beneficio de la Paz; y, iii) un cumplimiento sagrado de los pactos celebrados para salir de la guerra.

En la Constitución Política de Colombia de 1991, desde su Preámbulo, se le reconoce a la Paz la condición de valor fundante cuando expresa que, el Pueblo de Colombia, en su calidad de Soberano, y para garantizar la Paz, aprueba dicha Constitución ${ }^{8}$.

Esa fundamentación axiológica en el valor de la $\mathrm{Paz}$, se materializa en dos elementos sumamente importantes: la naturaleza de la Constitución como un tratado de $\mathrm{Paz}^{9}$ y la relación tríadica que en torno a ella se construye en el ordenamiento jurídico a partir de los derechos, los deberes y los mecanismos de protección ${ }^{10}$.

\section{2) LA PAZ COMO PRINCIPIO}

En la Constitución Política de 1991, la Paz adquiere la dimensión cualitativa de ser un principio del ordenamiento jurídico superior. En este

8 En Colombia, se vino a reconocer la fuerza vinculante del Preámbulo por la jurisprudencia desde el año 1992 cuando se recurrió a este como parámetro de control de constitucionalidad, abandonando la histórica tradición de verla como un mero programa sin carácter vinculante. Corte Constitucional. 13 de agosto de 1992. "Demandas de inconstitucionalidad acumuladas contra el artículo 20 de la ley 60 de 1990 y el Decreto Ley 1660 de 1991". Sentencia C-479 de 1992. Disponible en http://www.corteconstitucional.gov.co/ relatoria/1992/C-479-92.htm [Fecha de visita 14 de mayo de 2014] pp. 28-32. En el mismo sentido véase Angulo Bossa, Jaime (2002) El Preámbulo de la Constitución Nacional. 2a ed. Bogotá: Temis. 541 pp.

9 Sobre la naturaleza de la Constitución Política de 1991 como tratado de Paz véase CorTe Constitucional. 30 de julio de 2002. "Revisión de la Ley 742 del 5 de junio de 2002 "Por medio de la cual se aprueba el Estatuto de Roma de la Corte Penal InternaCIONAL, hecho en Roma el día diecisiete (17) de julio de mil novecientos noventa y ocho (1998)". Sentencia C-578 de 2002. Disponible en http://www.corteconstitucional.gov. co/relatoria/2002/C-578-02.htm [Fecha de visita 14 de mayo de 2014] p. 102 y CorTe Constitucional 18 de mayo de 2006. "Demanda de inconstitucionalidad contra los artículos 2, 3, 5, 9, 10,11.5, 13, 16, 17, 18, 19, 20, 21, 22, 23, 24, 25, 26, 27, 28, 31, 34, 37 numerales 5 y 7, 46, 47, 48, 54, 55, 58, 62, 69, 70 y 71 de la Ley 975 de 2005 "Por la cual se dictan disposiciones para la reincorporación de miembros de grupos armados organizados al margen de la ley, que contribuyan de manera efectiva a la consecución de la paz nacional y se dictan otras disposiciones para acuerdos humanitarios", y contra la ley en su integridad". Sentencia C-370 de 2006. Disponible e http://www.corteconstitucional.gov.co/ relatoria/2006/C-370-06.htm [Fecha de visita 14 de mayo de 2014] pp. 235, 285, 299.

10 Véase Corte Constitucional. 7 de noviembre de 1997. "Demanda de inconstitucionalidad contra los artículos 40 (parcial), 23, 24, 25, 26, 27, 28, 29, 39, 40, 41, 42, 43, 44, 45 у 46 del Decreto 356 del 11 de febrero de 1994, "Por el cual se expide el Estatuto de Vigilancia y Seguridad Privada". Sentencia C-572 de 1997. Disponible en http://www.corteconstitucional.gov.co/relatoria/1997/C-572-97.htm [Fecha de visita 14 de mayo de 2014] p. 51. 
sentido, adquiere dos connotaciones: como derecho fundamental y como derecho colectivo.

Como derecho fundamental, no solo está ubicado en el Art. 22 (criterio de la ubicación ${ }^{11}$ ), sino que además el Art. 377 prevé que cualquier modificación a este puede ser objeto de referendo derogatorio (criterio del plus para la reforma ${ }^{12}$ ), además de estar consignado en diversos tratados sobre derechos humanos de los cuales Colombia es parte (criterio de la inclusión en los tratados internacionales que conforman el bloque de constitucionalidad $\left.{ }^{13}\right)^{14}$.

Refiriéndose al ámbito interno, reconoció la Corte Constitucional que la Paz es un derecho fundamental, en tanto condición necesaria para el ejercicio de otros derechos ${ }^{15}$.

Aunque esta no es una posición unificada del alto tribunal, toda vez que previamente había dicho que, pese a su inclusión en el Capítulo I del Título II, ella no era, por su naturaleza, un derecho fundamental y que, por ende, no tenía reserva de ley estatutaria ${ }^{16}$, también manifestó en otra

11 Dice el Art. 22 lo siguiente: "ARTÍCULO 22. La paz es un derecho y un deber de obligatorio cumplimiento". Disponible en http://www.secretariasenado.gov.co/senado/basedoc/constitucion_politica_1991.html\#22

12 Dice el Art. 377 lo siguiente: “ARTÍCULO 377. Deberán someterse a referendo las reformas constitucionales aprobadas por el Congreso, cuando se refieran a los derechos reconocidos en el Capitulo 1 del Título II y a sus garantias, a los procedimientos de participación popular, o al Congreso, si asi lo solicita, dentro de los seis meses siguientes a la promulgación del Acto Legislativo, un cinco por ciento de los ciudadanos que integren el censo electoral. La reforma se entenderá derogada por el voto negativo de la mayoría de los sufragantes, siempre que en la votación hubiere participado al menos la cuarta parte del censo electoral'. Disponible en http://www.secretariasenado.gov.co/senado/basedoc/constitucion_politica_1991_pr012.html\#377

13 Dice el Art. 93 lo siguiente: “ARTÍCULO 93. Los tratados y convenios internacionales ratificados por el Congreso, que reconocen los derechos humanos y que prohiben su limitación en los estados de excepción, prevalecen en el orden interno. Los derechos y deberes consagrados en esta Carta, se interpretarán de conformidad con los tratados internacionales sobre derechos humanos ratificados por Colombia". Disponible en http://www.secretariasenado.gov.co/senado/basedoc/constitucion_politica_1991_pr002.html\#93

14 Véase Corte Constitucional. 8 de mayo de 1992. "Proceso de tutela, adelantada por Pastora Emilia Upegui Noreña”. Sentencia T-002 de 1992. Disponible en http://www.corteconstitucional.gov.co/relatoria/1992/T-002-92.htm [fecha de consulta 14 de mayo de 1992] pp. 5-13. Una explicación de los criterios para el reconocimiento de derechos fundamentales en la Constitución de 1991 en Moreno Millán, Franklin (2010) "De los derechos fundamentales en la Constitución de 1991”, Revista Aequitas. Universidad Santiago de Cali. Año 1 No. 1. 55-74 pp.

15 Corte Constitucional. 2 de julio de 1992. "Proceso de tutela T-1088 adelantado por el señor Luis Humberto Rolon Maldonado contra las Fuerzas Militares de Colombia y los Organismos de Seguridad del Estado con sede en el Departamento de Norte de Santander". Sentencia T-439 de 1992. Disponible en http://www.corteconstitucional.gov.co/ relatoria/1992/T-439-92.htm [Fecha de visita 14 de mayo de 2014] p. 10.

16 La ley estatutaria es un tipo especial de ley que se utiliza en Colombia para reglamentar, entre otros, los derechos fundamentales. Véase Sierra Porto, Humberto Antonio (1998) Concepto y tipos de ley en la Constitución colombiana. Bogotá: Universidad Externado de Colombia, 426 pp., 282. En el mismo sentido Corte Constitucional. 16 de febrero de 1995. "Demanda de inconstitucionalidad contra la Ley 104 de 1993". Sentencia C-055 de 
oportunidad que la Paz, como derecho social, esto es, que se expresa como "convivencia ordenada entre los ciudadanos", se distinguía de la tranquilidad que sí constituye derecho subjetivo, en tanto que no puede ser protegida mediante la acción de tutela salvo que se evidencie amenaza de perjuicio irremediable, con lo cual deja entrever que el problema no es tanto la naturaleza del derecho a la Paz sino su mecanismo de protección ${ }^{17}$.

Para reforzar esta posición, expresó el alto tribunal que la Paz es un deber ciudadano (Art. 95-6 de la CP), predicable de las autoridades públicas y de todos los habitantes del territorio nacional ${ }^{18}$.

En conclusión, la Paz es un derecho fundamental cuya protección no se puede hacer en las mismas condiciones que otros derechos de contenido hermenéutico menos problemático, pero que en el evento de un perjuicio irremediable y ligado con el contenido de otros derechos puede ser objeto de protección, incluso mediante la acción de tutela ${ }^{19}$.

En el ámbito internacional, la Declaración de Oslo sobre el Derecho Humano a la Paz, aprobada por la Conferencia General de la Organización de las Naciones Unidas para la Educación la Ciencia y la Cultura,

1995. Disponible en http://www.corteconstitucional.gov.co/relatoria/1995/C-055-95.htm [Fecha de consulta 14 de mayo de 2014] p. 70. También Corte Constitucional. 18 de mayo de 1992. "Revisión de la sentencia proferida por el Honorable Tribunal Superior del Distrito de Santafé de Bogotá D.C”. Sentencia T-008 de 1992. Disponible en http://www. corteconstitucional.gov.co/relatoria/1992/T-008-92.htm [Fecha de consulta 14 de mayo de 2014] p. 22.

17 Corte Constitucional. 25 de mayo de 1995. "Amparo del derecho al medio ambiente libre de ruido, y su concurrencia con otros derechos como la tranquilidad y la salud". Sentencia T-226 de 1995. Disponible en http://www.corteconstitucional.gov.co/ relatoria/1995/T-226-95.htm [Fecha de consulta 14 de mayo de 2014] p. 7.

18 Corte Constitucional. 6 de julio de 1995. "Demanda de inconstitucionalidad contra la Ley 104 de 1993 "por la cual se consagran unos instrumentos para la búsqueda de la convivencia, la eficacia de la justicia y se dictan otras disposiciones"”. Sentencia C-283 de 1995. Disponible en http://www.corteconstitucional.gov.co/relatoria/1995/C-283-95.htm [Fecha de consulta 14 de mayo de 1995] p. 49. En el mismo sentido Corte Constitucional. 13 de julio de 2006. "Demanda de inconstitucionalidad contra los artículos 2, 3, 5, 9, 10, $11.5,13,16,17,18,19,20,21,22,23,24,25,26,27,28,31,34,37$ numerales 5 y 7,46 , 47, 48, 54, 55, 58, 62, 69, 70 y 71 de la Ley 975 de 2005 "Por la cual se dictan disposiciones para la reincorporación de miembros de grupos armados organizados al margen de la ley, que contribuyan de manera efectiva a la consecución de la paz nacional y se dictan otras disposiciones para acuerdos humanitarios", y contra la ley en su integridad". Sentencia C-370 de 2006. Disponible en http://www.corteconstitucional.gov.co/relatoria/2006/C-370-06.htm [Fecha de consulta 14 de mayo de 2014] p. 235, 285, 299.

19 De conformidad con el Art. 86 de la Constitución Política de Colombia, la acción de tutela es el mecanismo judicial de defensa de los derechos fundamentales cuando quiera que estos resulten vulnerados por la acción o la omisión de una autoridad pública o de un particular, no existe mecanismo ordinario de defensa o este no resulte idóneo en el caso concreto y se esté ante un perjuicio irremediable. Sobre la tutela como mecanismo de protección de derechos fundamentales véase, en Colombia, Dueñas Ruiz, Óscar José (2005) Acción y procedimiento en la tutela. $4^{a}$ ed. Bogotá: Ediciones Librería del Profesional. 595 pp., p. 43. Asimismo, Osuna Patiño, Néstor Iván (1998) Tutela y amparo. Derechos protegidos. Bogotá: Universidad Externado de Colombia. 368 pp. p., 196. 
en 29a Celebrada en París del 21 de octubre al 12 de noviembre de 1997, expresa en su Art. $1^{\circ}$ que la Paz es un derecho humano, inherente a su dignidad, que excluye todo tipo de guerra y de conflicto armado y que se debe garantizar sin ningún tipo de discriminación.

Como derecho colectivo, la Paz adquiere tal condición a partir de diversos elementos.

En primer lugar, pertenece a los derechos de tercera generación porque su titularidad y ejercicio no se predica de personas individualmente consideradas ${ }^{20}$.

En segundo lugar, porque su materialización requiere de variados elementos sociales, políticos, económicos e ideológicos, siendo susceptible además de protección por medio de la acción popular ${ }^{21}$.

En tercer lugar, porque ella es un presupuesto lógico de la verdad, la justicia y la reparación, sobre todo cuando la indemnización queda a un segundo plano y adquiere mayor relevancia la convivencia pacífica que la entrega de recursos a título de reparación del daño 22 .

En cuarto lugar, en tanto al ser un bien colectivo, las autoridades públicas también son responsables de su conservación ${ }^{23}$.

20 Corte Constitucional. 13 de julio de 2006. "Demanda de inconstitucionalidad contra los artículos 2, 3, 5, 9, 10, 11.5, 13, 16, 17, 18, 19, 20, 21, 22, 23, 24, 25, 26, 27, 28, 31, 34, 37 numerales 5 y 7, 46, 47, 48, 54, 55, 58, 62, 69, 70 y 71 de la Ley 975 de 2005 "Por la cual se dictan disposiciones para la reincorporación de miembros de grupos armados organizados al margen de la ley, que contribuyan de manera efectiva a la consecución de la paz nacional y se dictan otras disposiciones para acuerdos humanitarios", y contra la ley en su integridad". Sentencia C-370 de 2006. Disponible en http://www.corteconstitucional.gov.co/ relatoria/2006/C-370-06.htm [Fecha de consulta 14 de mayo de 2014] p. 236. Mediante Decreto Ley 2591 de 1991, se reglamentó en Colombia el ejercicio de la acción de tutela, mecanismo extraordinario de protección de los derechos fundamentales. En su Artículo 6º consagra las causales de rechazo y entre ellas el numeral 3 prevé que la misma no procede "3. Cuando se pretenda proteger derechos colectivos, tales como la paz (...)" lo cual reafirma que no se trata de un derecho fundamental. Disponible en www.corteconstitucional.gov.co/ lacorte/DECRETO\%202591.php

21 Corte Constitucional. 18 de mayo de 1992. "Revisión de la sentencia proferida por el Honorable Tribunal Superior del Distrito de Santafé de Bogotá D.C”. Sentencia T-008 de 1992. Disponible en http://www.corteconstitucional.gov.co/relatoria/1992/T-008-92.htm [Fecha de consulta 14 de mayo de 2014] p. 9. Prevista en el Artículo 88 de la Constitución Política de 1991 y reglamentada mediante Ley 472 de 1997, la acción popular es la herramienta judicial de protección de los derechos colectivos y de medio ambiente en Colombia. Disponible en www.alcaldiabogota.gov.co/sisjur/normas/Norma1.jsp?i=188

22 Corte Constitucional. 30 de julio de 2002. "Revisión de la Ley 742 del 5 de junio de 2002 "Por medio de la cual se aprueba el Estatuto de Roma de la Corte Penal InterNACiOnal, hecho en Roma el día diecisiete (17) de julio de mil novecientos noventa y ocho (1998)". Sentencia C-578 de 2002. Disponible en http://www.corteconstitucional.gov.co/ relatoria/2002/C-578-02.htm [Fecha de consulta 14 de mayo de 2014] p. 74.

23 Corte Constitucional. 19 de mayo de 1995. "Revisión constitucional del "Protocolo adicional a los Convenios de Ginebra del 12 de agosto de 1949, relativo a la protección de las víctimas de los conflictos armados sin carácter internacional (Protocolo II)" hecho en Ginebra el 8 de junio de 1977, y de la Ley 171 del 16 de diciembre de 1994, por medio de la cual se aprueba dicho Protocolo". Sentencia C-225 de 1995. Disponible en http://www. 
En quinto lugar, porque limita la independencia judicial, toda vez que en aquellos casos donde la Paz colectiva esté inmersa se debe permitir la participación de la comunidad a través de un actor popular dentro del proceso penal ${ }^{24}$.

En sexto lugar, toda vez que al ser un interés jurídico colectivo, cualquier persona puede actuar a nombre de la comunidad dentro del proceso penal donde se juzguen violaciones colectivas a los derechos humanos, siempre que, para evitar enfrentamiento de intereses particulares, el actor demuestre que se mueve con el único móvil del esclarecimiento de los hechos investigados y la protección de valores, entre ellos, precisamente, la Paz colectiva ${ }^{25}$.

En séptimo lugar, porque su evaluación de su existencia parte de tres elementos: (i) el respeto a los derechos humanos, (ii) el control al uso de la fuerza y (iii) el logro de la seguridad colectiva ${ }^{26}$.

Con estas consideraciones, la Paz se reconoce como derecho colectivo susceptible de ser protegida mediante la acción popular, excepcionalmente mediante acción de tutela pero, de manera muy especial, mediante la toma de decisiones gubernamentales que permitan una construcción colectiva del consenso y una superación paulatina de la barbarie.

\section{2) Significado de la PAZ}

Para la Real Academia Española de la Lengua, un significado es el "Contenido semántico de cualquier tipo de signo, condicionado por el siste-

corteconstitucional.gov.co/relatoria/1995/C-225-95.htm [Fecha de consulta 14 de mayo de 2014] pp. 99-102.

24 Corte Constitucional. 21 de marzo de 2003. "Acción de tutela instaurada por Javier Giraldo Moreno en contra del Fiscal General de la Nación”. Sentencia T-249 de 2003. Disponible en http://www.corteconstitucional.gov.co/relatoria/2003/T-249-03.htm [Fecha de consulta 14 de mayo de 2014] p. 26. En Colombia, en los términos de la Ley 472 de 1997, "por la cual se desarrolla el artículo 88 de la Constitución Politica de Colombia en relación con el ejercicio de las acciones populares y de grupo y se dictan otras disposiciones" actor popular es la persona que inicia la acción popular para la defensa de derechos colectivos y del medio ambiente. Sobre la acción popular como mecanismo de defensa de los derechos colectivos en Colombia véase Camargo, Pedro Pablo (1999) Las acciones populares y de grupo. Bogotá: Leyer, 333 pp., p. 169.

25 Corte Constitucional. 28 de junio de 2005. "Proceso de revisión del fallo de tutela proferido por la Sala de Casación Penal de la Corte Suprema de Justicia, en relación con la acción tutelar impetrada por la Asociación para la Promoción Social Alternativa Minga, contra el Fiscal Delegado de la Unidad de los Derechos Humanos de la Fiscalía General de la Nación y el Fiscal 42 Delegado ante el Tribunal Superior de Bogotá". Sentencia T-589 de 2005. Disponible en http://www.corteconstitucional.gov.co/relatoria/2005/T-589-05.htm [Fecha de consulta 14 de mayo de 2014] pp. 38-39.

26 Corte Constitucional. 21 de marzo de 2003. "Acción de tutela instaurada por Javier Giraldo Moreno en contra del Fiscal General de la Nación”. Sentencia T-249 de 2003. Disponible en http://www.corteconstitucional.gov.co/relatoria/2003/T-249-03.htm [Fecha de consulta 14 de mayo de 2014] p. 26. 
ma y por el contexto" 27 . El principal problema de enunciar significados o conceptos, es que se puede restringir o exceder los límites de lo que se define o confundirlo con otros institutos, de allí que se aconseje señalar los elementos de la esencia para construir, a partir de allí, un acercamiento teórico a la ontología del instituto ${ }^{28}$.

Por eso, se señalarán las diferentes definiciones de Paz que utiliza la Corte Constitucional de Colombia, explicando previa y brevemente el sustento teórico desde el cual se enuncian y partiendo de la base que, incluso para el mismo tribunal, se trata de un concepto polivalente que no alcanza en el contexto colombiano un desarrollo dogmático definitivo.

\section{1) Polivalencia de Significados en la Constitución PolíticA DE 1991}

Para la Corte Constitucional ${ }^{29}$, la $\mathrm{Paz}$ se puede entender de diversas maneras: (i) como fin o propósito, tanto del derecho interno como del derecho internacional (ii) como estado ideal, (iii) como protocolo de actuación en medio de los conflictos, (iv) como derecho colectivo, (v) como derecho fundamental o subjetivo y (vi) como deber ciudadano o constitucional.

Esta clasificación no necesariamente está fundada en criterios hermenéuticos que permitan establecer la distinción entre unos y otros, al contrario, algunos podrían significar lo mismo y otros tendrían relaciones consecuenciales. Así por ejemplo, la Paz es un valor que tiende hacia un estado ideal y es un derecho que prevé un deber correlativo.

Por ello, al considerar la Paz como un concepto polivalente, que adquiere diferentes dimensiones, cualidades y fuerza vinculante según sea el

27 Tomado de http://www.rae.es/rae.html Consulta 3/10/2013.

28 Moreno Millán, Franklin (2013) La acción ciudadana de inconstitucionalidad. Devenir dogmático. Cali: Universidad de San Buenaventura, 107 pp., p. 29. En el mismo sentido, Bоввіо, Norberto (1981) El problema de la guerra y las vías de la paz. Traducción de Jorge Binaghi. Barcelona: Gedisa editorial, 204 pp. p., 158.

29 Corte Constitucional 18 de mayo de 2006. "Demanda de inconstitucionalidad contra los artículos 2, 3, 5, 9, 10, 11.5, 13, 16, 17, 18, 19, 20, 21, 22, 23, 24, 25, 26, 27, 28, 31, 34, 37 numerales 5 y 7, 46, 47, 48, 54, 55, 58, 62, 69, 70 y 71 de la Ley 975 de 2005 "Por la cual se dictan disposiciones para la reincorporación de miembros de grupos armados organizados al margen de la ley, que contribuyan de manera efectiva a la consecución de la paz nacional y se dictan otras disposiciones para acuerdos humanitarios", y contra la ley en su integridad". Sentencia C-370 de 2006. Disponible e http://www.corteconstitucional.gov.co/ relatoria/2006/C-370-06.htm [Fecha de visita 14 de mayo de 2014] pp. 239. Corte ConsTitucional. 24 de enero de 2001. "Demanda de inconstitucionalidad contra el artículo 8 (parcial) de la Ley 418 de 1997”. Sentencia C-048 de 2001. Disponible en http://www. corteconstitucional.gov.co/relatoria/2001/C-048-01.htm [Fecha de consulta 14 de mayo de 2014] p. 27. Igualmente Corte Constitucional. 6 de septiembre de 2005. "Demanda de inconstitucionalidad contra el Art. 19 (parcial) de la Ley 782 de 2002”. Sentencia C-928 de 2005. Disponible en http:/www.corteconstitucional.gov.co/relatoria/2005/C-928-05.htm [Fecha de consulta 14 de mayo de 2014] p. 17. 
contexto desde el que se mire, los sujetos que involucra, las herramientas de protección y el fin que persigue, sirviendo incluso como parámetro directo del control de constitucionalidad de las normas ${ }^{30}$ y con la intención de acercarnos a un concepto genérico de Paz, daremos una mirada un poco más detallada según el devenir jurisprudencial de la Corte Constitucional colombiana que nos permita acercarnos a un concepto fuerte de Paz en la CP de 1991.

\subsection{1) La Paz como valor o estado ideal pretendido tanto por el derecho interno como por el Derecho Internacional}

Un valor es visto no como un objeto ideal sino como un fin o propósito, que va más allá de la subjetividad o de aceptaciones individuales para convertirse en objetivos colectivos ${ }^{31} \mathrm{o}$, en términos de su funcionalidad, como "el catálogo axiológico a partir del cual se deriva el sentido y la finalidad de las demás normas del ordenamiento jurídico" 32 . Es decir, los valores pueden tener función creadora, en la medida que a partir de sus enunciados se proyectan y materializan situaciones fácticas y jurídicas, así como función interpretativa por cuanto condicionan el entendimiento del ordenamiento jurídico.

El reconocimiento de la Paz como valor constitucional, no es un capricho interpretativo de la Corte Constitucional ni mucho menos una mutación constitucional $^{33}$. Diversos artículos aluden a la Paz en sus diversas orientaciones, entre ellos, el Preámbulo y el Artículo $2^{\circ}$ dejan entrever la importancia que dentro de la arquitectura constitucional tiene el valor de la Paz.

El valor de la Paz pretende alcanzar un estado ideal, en tal sentido utópico, en el concepto Moriano de la expresión ${ }^{34}$. Esta situación ideal,

30 Por ejemplo, la Corte Constitucional, en el año 2005, declaró la exequibilidad condicionada del Art. 19 de la Ley 782 de 2002, mediante el cual se permitía el otorgamiento del indulto a delitos no políticos, lo cual se consideró contrario al valor de la paz. Corte ConstitucioNAL. 6 de septiembre de 2005. "Demanda de inconstitucionalidad contra el Art. 19 (parcial) de la Ley 782 de 2002”. Sentencia C-928 de 2005. Disponible en http://www.corteconstitucional.gov.co/relatoria/2005/C-928-05.htm [Fecha de visita 14 de mayo de 2014] p. 18.

31 Ferrater Mora, José (1965) Diccionario de filosofía. Tomo II. Buenos Aires: Sudamericana, 1005 pp. p., 867.

32 Corte Constitucional. 5 de junio de 1992. "Proceso de acción de tutela promovido por el señor José Manuel Rodríguez Rangel contra el señor Enrique Chartuny González, gerente de las Empresas Públicas de Cartagena”. Sentencia T-406 de 1992. Disponible en http:// www.corteconstitucional.gov.co/relatoria/1992/T-406-92.htm [Fecha de visita 14 de mayo de 2014] p. 10.

33 Una mutación es una modificación de la Constitución que deja intacto su texto. Al respecto véase Jellinek, Georg (2006) Reforma y mutación de la Constitución. Traducción de Christian Förster. Bogotá: Leyer, 114 pp., p 13.

34 Moro, Tomás (2005). Utopia. Traducción moderna de Guillermo Rovirosa. Disponible en http://www.laeditorialvirtual.com.ar/pages/Moro_Tomas/TomasMoro_Utopia.htm [Fecha de consulta 3 de octubre de 2013], Sin número de páginas. 


\section{conocida como Paz negativa ${ }^{35}$, que se traduce en la ausencia de conflictos $^{36}$}

35 Sobre la Paz negativa, entendida como ausencia de conflictos y Paz positiva como la existencia de condiciones materiales para la superación del conflicto véase Ríos Sierra, Jerónimo; Bula Escobar, Germán; Brocate Pirón, Roberto. "Estado, Estado de Derecho y Violencia Armada en Colombia". Revista de Paz y Conflictos. Disponible en www.ugr.es/.../Estado_de_ derecho_violencia_armada_colombia.html. [Tomado 12/5/2014).

36 Sobre la Paz como ausencia de conflictos véase Corte Constitucional. 10 de agosto de 1994. "Revisión Constitucional del proyecto de ley estatutaria No. 214 de 1994 Cámara y 183 de 1994 Senado "Por la cual se expiden algunas disposiciones en materia electoral”. Sentencia C-353 de 1994. Disponible en http://www.corteconstitucional.gov.co/ relatoria/1994/C-353-94.htm [Fecha de visita 14 de mayo de 2014]; Corte ConstitucioNAL. 8 de febrero de 1996. "Revisión constitucional del Decreto 1902 del 2 de noviembre de 1995, "por el cual se toman medidas en materia de información y se dictan otras disposiciones". Sentencia C-045, 1996. Disponible en http://www.corteconstitucional.gov.co/ relatoria/1996/C-045-96.htm [Fecha de visita 14 de mayo de 2014] p. 19; Corte Constitucional. 22 de marzo de 2000. "Revisión de la Ley 525 de 1999 "Por medio de la cual se aprueba la "Convención sobre la prohibición del desarrollo, la producción, el almacenamiento y el empleo de armas químicas y sobre su destrucción”, hecho en París el trece (13) de enero de mil novecientos noventa y tres (1993)". Sentencia C-328 de 2000. Disponible en http://www.corteconstitucional.gov.co/relatoria/2000/C-328-00.htm [Fecha de visita 14 de mayo de 2014] p. 18; Corte Constitucional SC-991 de 2000. 2 de agosto de 2000. "Revisión constitucional de la Ley 554 del 14 de enero de 2000 "Por medio de la cual se aprueba la "Convención sobre la prohibición del empleo, almacenamiento, producción y transferencia de minas antipersonal y sobre su destrucción”, hecha en Oslo el dieciocho (18) de septiembre de mil novecientos noventa y siete (1997)". Disponible en http://www.corteconstitucional.gov.co/relatoria/2000/C-991-00.htm [Fecha de visita 14 de mayo de 2014] p. 43; Corte Constitucional. 24 de enero de 2001. "Demanda de inconstitucionalidad contra el artículo 8 (parcial) de la Ley 418 de 1997”. Sentencia C-048 de 2001. Disponible en http://www.corteconstitucional.gov.co/relatoria/2001/C-048-01.htm [Fecha de consulta 14 de mayo de 2014] p. 28; Corte Constitucional 28 de agosto de 2002. "Demanda de inconstitucionalidad contra el artículo 13 de la Ley 733 de 2002". Sentencia C-695 de 2002. Disponible en http://www.corteconstitucional.gov.co/relatoria/2002/C-695-02.htm [Fecha de visita 14 de mayo de 2014] p. 54; Corte Constitucional. 16 de mayo de 2006. "Demanda de inconstitucionalidad contra los artículos $1^{\circ}$, parcial; 2º, parcial; 12, parcial; 22, parcial; 26, parcial; 31, parcial y 80, parcial de la ley 916 de 2004, "Por la cual se establece el reglamento nacional taurino.”.". Sentencia C-367 de 2006. Disponible en http://www. corteconstitucional.gov.co/relatoria/2006/C-367-06.htm [Fecha de visita 14 de mayo de $2014]$ p. 27.

Corte Constitucional. 18 de mayo de 2006. "Demanda de inconstitucionalidad contra los artículos 2, 3, 5, 9, 10, 11.5, 13, 16, 17, 18, 19, 20, 21, 22, 23, 24, 25, 26, 27, 28, 31, 34, 37 numerales 5 y 7, 46, 47, 48, 54, 55, 58, 62, 69, 70 y 71 de la Ley 975 de 2005 "Por la cual se dictan disposiciones para la reincorporación de miembros de grupos armados organizados al margen de la ley, que contribuyan de manera efectiva a la consecución de la paz nacional y se dictan otras disposiciones para acuerdos humanitarios", y contra la ley en su integridad”. Sentencia C-370 de 2006. Disponible en http://www.corteconstitucional. gov.co/relatoria/2006/C-370-06.htm [Fecha de visita 14 de mayo de 2014] p. 236; CorTE Constitucional. 3 de diciembre de 2007. "Acción de tutela instaurada por Javier Giraldo Moreno contra el Ministerio de Defensa Nacional”. Sentencia T-1025 de 2007. Disponible en http://www.corteconstitucional.gov.co/relatoria/2007/T-1025-07.htm [Fecha de visita 14 de mayo de 2014]; Corte Constitucional. 9 de mayo de 2012. "Demanda de inconstitucionalidad contra los incisos $1^{\circ}$ y $3^{\circ}$ del artículo 67 de la Ley 975 de 2005 "por la cual se dicta disposiciones para la reincorporación de miembros de grupos armados organizados al margen de la ley, que contribuyan de manera efectiva a la consecución de la paz nacional y se dictan otras disposiciones para acuerdos humanitarios". Sentencia C-333 de 2012. Disponible 
(sentido amplio) o como ausencia de guerra $^{37}$ (sentido estricto) (y de aquí que se hable del sentido Moriano), lleva no solo a la negación del conflicto como hipótesis social, a su rechazo, sino a la prohibición de toda forma de expresión, de protección o de apología de la violencia como antítesis de la Paz.

Remontándonos a su origen griego, la idea de la Paz como ausencia de conflictos o idea panhelénica de la Paz (siglos V y VI a.C.), estuvo fuertemente marcada por el desprecio de la guerra y por la permanente búsqueda de la armonía ${ }^{38}$.

Esta idea de "ausencia de guerra", sin embargo, pudo haber sido motivada más por el debilitamiento de las comunidades griegas frente a los persas a consecuencia de las luchas intestinas y por la amenaza latente de la autodestrucción que por un resurgir antropocéntrico del Estado o por un afianzamiento de la idea de civilización. Así lo denunció Isócrates ${ }^{39}$ cuando manifestó en su discurso sobre la Paz la existencia de hombres inclinados a la guerra, que buscaban a través de ella recuperar lo que en otrora tuvieron. Pero también, el mismo Isócrates mandaba, para garantizar la Paz, a hacer la guerra en común contra los bárbaros y a ser superiores a sus enemigos ${ }^{40}$.

La idea de la Paz, por la razón que fuera, ocupó un importante lugar en la Escuela de los Sofistas. Pensadores como Tucídides reflejaron el pensamiento griego cuando recalcaron sobre la necedad de la guerra ${ }^{41}$.

en http://www.corteconstitucional.gov.co/relatoria/2012/C-333-12.htm [Fecha de visita 14 de mayo de 2014] p. 20.

37 Sobre la Paz como ausencia de guerra véase Corte Constitucional 22 de marzo de 2000 "Revisión de la Ley 525 de 1999 "Por medio de la cual se aprueba la "Convención sobre la prohibición del desarrollo, la producción, el almacenamiento y el empleo de armas químicas y sobre su destrucción", hecho en París el trece (13) de enero de mil novecientos noventa y tres (1993)". Sentencia C-328 de 2000. Disponible en http://www.corteconstitucional. gov.co/relatoria/2000/C-328-00.htm [Fecha de visita 14 de mayo de 2014] p. 18; CorTe Constitucional. 8 de julio de 2004. "Revisión constitucional de la Ley 846 de noviembre 6 de 2003, "por medio de la cual se aprueba el 'Protocolo Adicional al Acuerdo de Cartagena', 'Compromiso de la Comunidad Andina por la Democracia', hecho en Oporto, Portugal, el diecisiete (17) de octubre de mil novecientos noventa y ocho (1998)". Sentencia C-644 de 2004. Disponible en http://www.corteconstitucional.gov.co/relatoria/2004/C-644-04.htm [Fecha de consulta 14 de mayo de 2014] p. 50; Conte Constitucional. 6 de septiembre de 2005. "Demanda de inconstitucionalidad contra el Art. 19 (parcial) de la Ley 782 de 2002". Sentencia C-928 de 2005. Disponible en http://www.corteconstitucional.gov.co/ relatoria/2005/C-928-05.htm [Fecha de consulta 14 de mayo de 2014] p. 17.

38 Varvaroussis, Paris (1996) La idea de la paz. Traducción de Claudia Marcela Restrepo. Bogotá: Temis, 174 pp., 13-14.

39 Isócrates (1982) Discursos. Traducción de Juan Manuel Guzmán Hermida. Madrid: Biblioteca Gredos. 521 pp. p. 239.

40 IsóCRATES (1982) 274.

41 Tucídides (1969): "Historia de la guerra del Peloponeso". Traducción, introducción y notas de David González Maeso. En Historiadores Griegos. Madrid: Aguilar S.A., 1265-1546 pp., p. $1390,1402$. 
Para la escuela socrática, por su parte, la Paz es la antítesis de la guerra. En este sentido, Platón considera que todo Estado se debe conducir de acuerdo con sus leyes y que, en tal sentido, estas deben ser justas para que excluyan cualquier manifestación de confrontación armada. La guerra, según expresa, solo acarrea desgracias ${ }^{42}$ y la única hipótesis en que esta es válida es cuando la misma es necesaria para vencer en el campo de batalla al enemigo ${ }^{43}$.

En el mismo sentido, Aristóteles ${ }^{44}$ manifiesta que la guerra tiene cabida siempre que sea necesaria para alcanzar la Paz, acogiendo la idea platónica de Paz como antítesis de la guerra.

Por su parte, Maquiavelo ${ }^{45}$, a quien no se podría catalogar precisamente como un precursor de la Paz, entiende esta como la ausencia de guerra, y la guerra como un valor necesario, consustancial con la anarquía, a través de la cual se restablece el orden y se evita la anarquía. Hobbes $^{46}$ se adhiere a esta perspectiva cuando manifiesta que la guerra es una manifestación del estado de beligerancia en el que viven los hombres.

Para Kant ${ }^{47}$, la Paz se prevé a partir de un orden jurídico global que excluya las guerras en cualquiera de sus manifestaciones. Como explica Habermas $^{48}$, para Kant, así como un tratado termina con una guerra, una asociación de paz debe eliminar para siempre el mal mismo de la guerra.

Kelsen expresa que "La paz es una situación que se caracteriza por la ausencia de la fuerza" ${ }^{49}$. Esta idea de Kelsen, sin embargo, descarta el uso de la fuerza o de los medios coercitivos pero aclara que ello se permite únicamente como sanción ante la transgresión de la norma de allí que señalara: "El Derecho es, en realidad, un orden para promover la paz, en el sentido de que prohibe a los miembros de una comunidad el uso de la fuerza

42 Platón (1980) “La República o el Estado". Tomo VII. Traducción de Juan David García Bacca. En: Obras Completas. Caracas: Facultad de Humanidades y Educación Universidad Central de Caracas. 1-304 pp., p. 282 y s.s.

43 Platón (1980). "Las leyes". Tomo X. Traducción de Juan David García Bacca. En: Obras Completas. Caracas: Facultad de Humanidades y Educación Universidad Central de Caracas. $1-518$ pp., p. 313.

44 Aristóteles (1967) La Politica. Versión de Natividad Massanés. 4a Edición. Barcelona: Editorial Iberia S.A., 306 pp., p. 157.

45 Machiavelli, Nicoló (1993) "The Prince". In Great Books of the Western World. No. 21. Chicago: Encyclopaedia Britannica, inc. 3-37 pp., p. 21.

46 Hовbes (1993) 84.

47 Kant, Immanuel (2007) La paz perpetua. Traducción de José Loya Mateos. Madrid: Mestas ediciones, 89 pp.

48 Habermas, Jürgen (1997). "La idea kantiana de paz perpetua. Desde la distancia histórica de doscientos años". Isegoría, no 16, pp. 61-90. Disponible en: isegoria.revistas.csic.es/index. php/isegorialarticleldownload/184/184 [ [Fecha de visita 15 de mayo de 2014] p. 62-63.

49 Kelsen, Hans (2008) La paz por medio del derecho. Traducción de Luis Echávarri. Madrid: Trotta, 155 pp., p. 39. 
(...). Sin embargo, no excluye de una manera absoluta el uso de la fuerza" 50 . Como señalan Ramón y De Lucas, para Kelsen la guerra tiene sentido en tanto sea la manifestación de la sanción jurídica por el desconocimiento del derecho ${ }^{51}$.

El acogimiento en Colombia de esta concepción de la Paz estuvo precedida por algunas experiencias en el Derecho Internacional donde ya tiene alguna tradición, por ejemplo, en el Estatuto del Tribunal Militar Internacional de Nuremberg de $1945^{52}$, especialmente su Artículo 6o donde fija la competencia del Tribunal respecto de lo que denomina "crimenes contra la paz", "crimenes de guerra" y "crimenes contra la humanidad", así como en la Convención sobre la Imprescriptibilidad de los Crimenes de Guerra y de los Crimenes de Lesa Humanidad ${ }^{3}$ y la Carta de las Naciones Unidas $^{54}$ en cuyo artículo 26 se proscribe el armamentismo así como las diversas resoluciones de la Asamblea General de las Naciones Unidas que versan sobre el tema, el Preámbulo de la Declaración Universal de Derechos Humanos $^{55}$, y tanto en el Preámbulo como en la Carta constitutiva de la Organización de Estados Americanos ${ }^{56}$, normas todas estas incorporadas en el ordenamiento interno colombiano producto de la integración entre el derecho interno y el derecho internacional, permitido en la CP a partir de la teoría monista con primacía de la Constitución ${ }^{57}$, con la teoría del bloque de constitucionalidad ${ }^{58}$ y con la incorporación del principio Pro Ho-

Kelsen, Hans (1943) Derecho y paz en las relaciones internacionales. Traducción de Florencio Acosta. México: Fondo de Cultura Económica, 209 pp., p. 33.

51 Ramón, Consuelo, De Lucas, Javier (2007) Querela pacis, perpetua? Una reivindicación del Derecho internacional. Valencia: Patrona Sud-Nord, 233 pp., p. 48-49.

52 Disponible en http://www.cruzroja.es/dih/pdf/estatuto_del_tribunal_militar_internacional_de_nuremberg.pdf consultada el 3/10/2013.

53 Disponible en http://www.tc.gob.pe/tratados/uni_ddhh/instru_alca_especifi_uni/instru_crimenes_guerra/lesa_humani.pdf consultado el 3/10/2013

54 Disponible en http://www.un.org/es/documents/charter/chapter5.shtml consultada 3/10/2013

55 Disponible en https://www.un.org/es/documents/udhr/ capturado 31/03/2014.

56 Disponible en www.oas.org/juridico/spanish/tratados/a-41.html capturado 31/03/2014.

57 Sobre esta véase Moreno Millán, Franklin (2011): "Fundamentos constitucionales de las relaciones internacionales del Estado colombiano". En Las relaciones internacionales de Colombia, una mirada politica y jurídica. Cali. Universidad Santiago de Cali. Cali. 171-188 pp. Asimismo, Corte Constitucional. 10 de agosto de 1998. "Revisión constitucional de la "Convención de Viena sobre el Derecho de los Tratados entre Estados y Organizaciones Internacionales o entre Organizaciones Internacionales", hecha en Viena el 21 de marzo de 1986" y de la Ley No 406 del 24 de octubre de 1997 por medio de la cual se aprueba dicha Convención." Sentencia C-400 de 1998. Disponible en http://www.corteconstitucional.gov. co/relatoria/1998/C-400-98.htm [Fecha de consulta 14 de mayo de 2014] p. 83. Verdross, Alfred (1955) Derecho Internacional Público. Traducción de Antonio Truyol y Serra. Madrid: Aguilar, 563 pp., p. 68. Rousseau, Charles, (1966): Derecho internacional público profundizado. Traducción de Delia García Daireaux. Buenos Aires: Editorial La Ley, 468 pp., p. 16.

58 Al respecto Uprimny Yepes, Rodrigo (2005) "El bloque de constitucionalidad en Colombia. Un análisis jurisprudencial y un ensayo de sistematización doctrinal". Disponible en: http:// www.dejusticia.org/index.php? $m o d o=$ interna\&tema $=$ sistema_judicial\&publicacion $=72$. $[\mathrm{Fe}-$ 
mine, los anteriores enunciados se proyectan tanto en el derecho interno como en el Derecho Internacional incorporado en nuestro ordenamiento jurídico.

En el ámbito del concepto, tendríamos que decir que, para la Corte Constitucional de Colombia, el concepto de Paz como estado ideal parte de la prevención del conflicto, del encauzamiento si este se presenta, de la organización o definición del conflicto y, claro está, de la superación de las secuelas que este deje en la población ${ }^{59}$.

Este encauzamiento, utópico, que parte de la aporía de la "bumanización de la guerra” es, desde esta perspectiva, el más alto significado de la paz ${ }^{60}$.

Con relación a las funciones del valor de la Paz, ha dicho la Corte Constitucional ${ }^{61}$, que tiene función creadora, toda vez que promueve una realidad fáctica consistente en la "ausencia de conflictos o enfrentamientos violentos", lo cual entiende como núcleo minimo, y como entramado normativo, en tanto supone la plena realización de los "mandatos de optimización contenidos en las normas de Derechos Humanos", a lo que denomina desarrollo máximo, así como la "atenuación de los rigores de la guerra" y

cha de consulta 1 de octubre de 2013] p. 35. Gutiérrez Beltrán, Andrés Mauricio (2007) El bloque de constitucionalidad. Concepto y fundamentos. Bogotá: Universidad Externado de Colombia, 94 pp. Un excelente análisis acerca de la incorporación de los principios en el bloque de constitucionalidad en Estrada Vélez, Sergio Iván (2006) Los principios jurídicos y el bloque de constitucionalidad. Medellín: Universidad de Medellín, $152 \mathrm{pp}$.

Corte Constitucional. 22 de marzo de 2000. "Revisión de la Ley 525 de 1999 "Por medio de la cual se aprueba la "Convención sobre la prohibición del desarrollo, la producción, el almacenamiento y el empleo de armas químicas y sobre su destrucción”, hecho en París el trece (13) de enero de mil novecientos noventa y tres (1993)". Sentencia C-328 de 2000. Disponible en http://www.corteconstitucional.gov.co/relatoria/2000/C-328-00.htm [Fecha de visita 14 de mayo de 2014] p. 19.

60 Conte Constitucional. 22 de marzo de 2000. "Revisión de la Ley 525 de 1999 "Por medio de la cual se aprueba la "Convención sobre la prohibición del desarrollo, la producción, el almacenamiento y el empleo de armas químicas y sobre su destrucción”, hecho en París el trece (13) de enero de mil novecientos noventa y tres (1993)". Sentencia C-328 de 2000. Disponible en http://www.corteconstitucional.gov.co/relatoria/2000/C-328-00.htm [Fecha de visita 14 de mayo de 2014] p. 19.

61 Corte Constitucional. 18 de mayo de 2006. "Demanda de inconstitucionalidad contra los artículos 2, 3, 5, 9, 10, 11.5, 13, 16, 17, 18, 19, 20, 21, 22, 23, 24, 25, 26, 27, 28, 31, 34, 37 numerales 5 y 7, 46, 47, 48, 54, 55, 58, 62, 69, 70 y 71 de la Ley 975 de 2005 "Por la cual se dictan disposiciones para la reincorporación de miembros de grupos armados organizados al margen de la ley, que contribuyan de manera efectiva a la consecución de la paz nacional y se dictan otras disposiciones para acuerdos humanitarios", y contra la ley en su integridad". Sentencia C-370 de 2006. Disponible e http://www.corteconstitucional.gov.co/ relatoria/2006/C-370-06.htm [Fecha de visita 14 de mayo de 2014] p. 235. En igual sentido, Corte Constitucional. 19 de mayo de 1995. "Revisión constitucional del "Protocolo adicional a los Convenios de Ginebra del 12 de agosto de 1949, relativo a la protección de las víctimas de los conflictos armados sin carácter internacional (Protocolo II)" hecho en Ginebra el 8 de junio de 1977, y de la Ley 171 del 16 de diciembre de 1994, por medio de la cual se aprueba dicho Protocolo". Sentencia C-225 de 1995. Disponible en http://www. corteconstitucional.gov.co/relatoria/1995/C-225-95.htm [Fecha de consulta 14 de mayo de 2014] p. 99. 
la muy problemática "humanización" de las situaciones de conflicto", producto de esta segunda expresión. Asimismo, le reconoció el carácter de parámetro de control de constitucionalidad, por ejemplo, cuando declaró la inconstitucionalidad parcial de una norma en tanto se restringía la libertad de prensa cuando esta se utilizara, en palabras de la Corte "para estimular las actividades ilicitas y en particular las conductas delictivas y la violencia en sus diversas manifestaciones, a través de la difusión de comunicados o declaraciones directa o indirectamente provenientes de sus actores" ${ }^{62}$. En tal sentido, dijo la Corte, a los medios de comunicación les corresponde informar a la comunidad, facilitar la consolidación de la Paz y evitar convertirse en "instrumentos de resonancia del terrorismo y del crimen organizado" que refuercen o legitimen el actuar de los violentos ${ }^{63}$.

De manera un poco más precisa, había dicho el alto tribunal que la Paz implica la posibilidad "de vivir en una sociedad que excluya la violencia como medio de solución de conflictos", con las respectivas consecuencias de poder denunciar todo acto de violencia y de recibir protección del Estado cuando esta se presente ${ }^{64}$.

62 Corte Constitucional. 8 de febrero de 1996. "Revisión constitucional del Decreto 1902 del 2 de noviembre de 1995, "por el cual se toman medidas en materia de información y se dictan otras disposiciones"”. Sentencia C-045, 1996. Disponible en http://www.corteconstitucional.gov.co/relatoria/1996/C-045-96.htm [Fecha de visita 14 de mayo de 2014] p. 19.

63 La Corte Constitucional revisó la Ley 104 de 1993 y, aunque declaró la inconstitucionalidad de ciertos artículos por vicios de procedimiento, vale destacar que los mismos traían una previsión en igual sentido. Véase Corte Constitucional. 29 de junio de 1995. "Demanda de inconstitucionalidad contra la Ley 104 de 1993 "por la cual se consagran unos instrumentos para la búsqueda de la convivencia, la eficacia de la justicia y se dictan otras disposiciones"”. Sentencia C-283 de 1995. Disponible en: http://www.corteconstitucional. gov.co/relatoria/1995/C-283-95.htm [Fecha de consulta 14 de mayo de 2014] p. 54.

64 Corte Constitucional. 10 de marzo de 1993. "Revisión de tutela contra la decisión adoptada por el Alcalde Municipal, el Comandante de la Policía y el Ministerio de Defensa, de construir el nuevo Comando de Policía en ese sector del Municipio”. Sentencia T-102 de 1993. Disponible en http://www.corteconstitucional.gov.co/relatoria/1993/T-102-93.htm [Fecha de consulta 14 de mayo de 2014] p. 13. En igual sentido Corte Constitucional. 24 de enero de 2001. "Demanda de inconstitucionalidad contra el artículo 8 (parcial) de la Ley 418 de 1997”. Sentencia C-048 de 2001. Disponible en http://www.corteconstitucional.gov.co/relatoria/2001/C-048-01.htm [Fecha de consulta 14 de mayo de 2014] p. 27. De manera particular, luego de que en el ańo 1997 se votara el mandato por la paz, la vida y la libertad, la Corte Constitucional tuvo la oportunidad de pronunciarse en dos ocasiones sobre normas que contrariaban dicho mandato. Al margen de los resultados del control, lo importante es señalar que en este mandato se veía la Paz como un estado ideal que superaba la etapa del conflicto armado. Véase Corte Constitucional. 8 de julio de 1998. "Demanda de inconstitucionalidad contra el artículo 10 , el parágrafo $1^{\circ}$ del artículo 14 y el parágrafo del artículo 20 de la Ley 48 de 1993". Sentencia C-339 de 1998. Disponible en http:// www.corteconstitucional.gov.co/relatoria/1998/C-339-98.htm [Fecha de consulta 14 de mayo de 2014] y Corte Constitucional. 8 de julio de 1998. "Acción pública de inconstitucionalidad ejercida por María Teresa Garcés Lloreda contra parte del artículo 13 de la Ley 418 de 1997”. Sentencia C-340 de 1998. Disponible en http://www.corteconstitucional. gov.co/relatoria/1998/C-340-98.htm [Fecha de consulta 14 de mayo de 2014] 
Finalmente, la Corte Constitucional ${ }^{65}$ acepta que la aplicación de mecanismos de justicia transicional conduce a "la terminación del conflicto armado interno y el logro de la paz" lo cual no excluye hacer uso de la Paz como principio lo que permite hacer "una ponderación explícita o implícita, entre la paz, la justicia y los derechos de las victimas".

Esta idea de la Paz como valor que pretende por un estado ideal, libre de guerra (sentido estricto) y de conflictos (sentido amplio) es, conjuntamente con la idea de la Paz como derecho, los dos grandes significados de la Paz en la CP de 1991.

\subsection{2) La Paz como protocolo de actuación en medio de los conflictos}

Un segundo sentido de la Paz, producto de la existencia inveterada de un conflicto armado, frente al cual la respuesta bélica resultó infructuosa, bien porque no logró desarticular sus expresiones, ora porque los resultados negativos de esta suponen un mayor quebrantamiento de valores y principios que los que se afectan con el conflicto o con una salida negociada al mismo es el de la Paz como protocolo de actuación o resolución de los conflictos.

Este escenario se presenta como la propuesta de una "negociación pacifica del conflicto"66, donde se reconoce que la Paz no es la ausencia de conflictos sino, desde una Paz positiva, la posibilidad de su resolución pacífica $^{67}$, que parte de la decisión democrática de optar por esta así como de la libre configuración de los mecanismos mediante los cuales se lleva a cabo, todo dentro del marco constitucional ${ }^{68}$.

65 Conte Constitucional. 28 de agosto de 2013. "Demanda de inconstitucionalidad contra el artículo $1^{\circ}$ del Acto Legislativo 1 de 2012 (parcial)”. Sentencia C-579 de 2013. Disponible en http://www.corteconstitucional.gov.co/relatoria/2013/C-579-13.htm [Fecha de consulta 14 de mayo de 2014] p. 146.

66 Corte Constitucional. 24 de enero de 2001. "Demanda de inconstitucionalidad contra el artículo 8 (parcial) de la Ley 418 de 1997". Sentencia C-048 de 2001. Disponible en http://www.corteconstitucional.gov.co/relatoria/2001/C-048-01.htm [Fecha de consulta 14 de mayo de 2014] p. 25.

Corte Constitucional. 9 de agosto de 2001. "Demanda de inconstitucionalidad contra el artículo $4^{\circ}$ de la ley 169 de 1.896”. Sentencia C-836 de 2001. Disponible en http://www. corteconstitucional.gov.co/relatoria/2001/C-836-01.htm [Fecha de visita 14 de mayo de 2014] pp. 19-38.

67 Corte Constitucional. 19 de mayo de 1995. "Revisión constitucional del "Protocolo adicional a los Convenios de Ginebra del 12 de agosto de 1949, relativo a la protección de las víctimas de los conflictos armados sin carácter internacional (Protocolo II)" hecho en Ginebra el 8 de junio de 1977, y de la Ley 171 del 16 de diciembre de 1994, por medio de la cual se aprueba dicho Protocolo". Sentencia C-225 de 1995. Disponible en http://www. corteconstitucional.gov.co/relatoria/1995/C-225-95.htm [Fecha de consulta 14 de mayo de $2014]$ p. 57.

68 En igual sentido Corte Constitucional. 19 de mayo de 1995. "Revisión constitucional del "Protocolo adicional a los Convenios de Ginebra del 12 de agosto de 1949, relativo a la protección de las víctimas de los conflictos armados sin carácter internacional (Protocolo 
Este proceso de salida negociada al conflicto (en oposición a la resolución bélica o como paralelo de una respuesta armada), hace parte de las posibilidades constitucionales de consecución de la Paz, a cargo especial pero no únicamente del Presidente de la República y con una clara preeminencia frente a otras medidas, lo que lleva a decir que constituye la Prima Ratio en las salidas constitucionales al conflicto.

Esta idea de la $\mathrm{Paz}$, no podría entonces estar sujeta a regulaciones o formalismos legales que desconozcan su naturaleza compleja, lo cual incluye desde la inclusión de plazos y el cumplimiento de excesivos trámites para la realización de encuentros de diálogo, por citar solo dos ejemplos; el mayor peso que ostenta frente a otras medidas constitucionalmente aceptadas, como proyectos políticos guerreristas y la obligación de no abandonar esta estrategia hasta que se hayan agotado fácticamente todas las posibilidades de acercamiento y negociación. Asimismo, y desde una perspectiva de las políticas públicas, la prohibición de proferir actos normativos que estimulen, inciten, promuevan o perpetúen la violencia armada como respuesta a los conflictos políticos y sociales ${ }^{69}$.

Lo anterior no significa que se tenga una Patente de Corso para salir negociadamente del conflicto. Como en todo proceso humano, en que dependiendo del fin así se escogen los medios, hay que partir del aforismo según el cual "la cura no puede ser mayor que la enfermedad".

La CP de 1991, como muchas constituciones occidentales, hizo acopio del principio de proporcionalidad para evaluar la legitimidad de todas aquellas medidas fácticas o normativas que intervinieran en el ejercicio de los derechos (entre ellos la Paz). Es así como la adopción de medidas para

II)" hecho en Ginebra el 8 de junio de 1977, y de la Ley 171 del 16 de diciembre de 1994, por medio de la cual se aprueba dicho Protocolo". Sentencia C-225 de 1995. Disponible en http://www.corteconstitucional.gov.co/relatoria/1995/C-225-95.htm [Fecha de consulta 14 de mayo de 2014] p. 102; Corte Constitucional. 2 de agosto de 2000. "Revisión constitucional de la Ley 554 del 14 de enero de 2000 "Por medio de la cual se aprueba la "Convención sobre la prohibición del empleo, almacenamiento, producción y transferencia de minas antipersonal y sobre su destrucción", hecha en Oslo el dieciocho (18) de septiembre de mil novecientos noventa y siete (1997)"'. Sentencia C-991 de 2000. Disponible en http://www.corteconstitucional.gov.co/relatoria/2000/C-991-00.htm [Fecha de visita 14 de mayo de 2014] p. 43; Corte Constitucional. 24 de enero de 2001. "Demanda de inconstitucionalidad contra el artículo 8 (parcial) de la Ley 418 de 1997”. Sentencia C-048 de 2001. Disponible en http://www.corteconstitucional.gov.co/relatoria/2001/C-048-01. htm [Fecha de consulta 14 de mayo de 2014] p. 27; Corte Constitucional. 30 de julio de 2002. "Revisión de la Ley 742 del 5 de junio de 2002 "Por medio de la cual se aprueba el Estatuto de Roma de la Corte Penal Internacional, hecho en Roma el día diecisiete (17) de julio de mil novecientos noventa y ocho (1998)". Sentencia C-578 de 2002. Disponible en http://www.corteconstitucional.gov.co/relatoria/2002/C-578-02.htm [Fecha de visita 14 de mayo de 2014] p. 102.

69 Corte Constitucional. 23 de septiembre de 1997. "Demanda de inconstitucionalidad contra el artículo 127 del decreto 100 de 1980 "Por medio del cual se expide el Código Penal"'. Sentencia C-456 de 1997. Disponible en http://www.corteconstitucional.gov.co/ relatoria/1997/C-456-97.htm [Fecha de consulta 14 de mayo de 2014] p. 39. 
la solución negociada del conflicto no pueden quebrantar valores y principios si ello no cumple no unos mínimos de adecuación y de necesidad. En tal sentido, las medidas que se adopten deben satisfacer los requisitos de idoneidad, necesidad y proporcionalidad ${ }^{70}$. Así por ejemplo, el respeto de la vida, la dignidad humana, el orden democrático, la vigencia del Estado constitucional, son mínimos que no se pueden desconocer cuando se adelanta la salida negociada al conflicto ${ }^{71}$.

$\mathrm{Al}$ margen de las anteriores consideraciones, la idea de la Paz como protocolo, es la misma idea de la Paz como principio, en tanto se trata de una norma axiológica que permite diversas interpretaciones pero que, en todo caso, tiene una textura argumentativa que permite se le lleve a casos concretos. Por eso, al final, esta idea será subsumida dentro de la idea general de la Paz como principio.

\subsection{3) La Paz como derecho colectivo}

Los derechos colectivos, llamados también de tercera generación o, más recientemente, "derechos de la humanidad" al tener como objeto garantías que no se pueden monopolizar individualmente y cuya titularidad corresponde a las generaciones presentes y futuras ${ }^{72}$ surgen en el contexto de la Declaración Universal de Derechos Humanos de 1948, como una contra respuesta al carácter interno de los derechos individuales y de los denominados derechos sociales, económicos y culturales.

Para el caso colombiano, son derechos colectivos los definidos como tal en la CP (Arts. 78-82), en la ley (Ley 472, 1998) y en los tratados de los cuales el Estado colombiano sea parte.

70 Bernal Pulido, Carlos (2007) El principio de proporcionalidad y los derechos fundamentales. $3^{\mathrm{a}}$ ed. Madrid: Centro de Estudios Políticos y Constitucionales, 883 pp. En el mismo sentido, Bernal Pulido, Carlos (2005) El derecho de los derechos. Bogotá: Universidad Externado de Colombia, 419 pp. En igual sentido Lópera Mesa, Gloria Patricia (2006) Principio de proporcionalidad y ley penal. Madrid: Centro de Estudios Políticos y Constitucionales, 661 pp. y Martínez Zorrilla, David (2007) Conflictos constitucionales, ponderación e indeterminación normativa. Madrid: Marcial Pons, 392 pp.

71 Corte Constitucional. 22 de marzo de 2000. "Revisión de la Ley 525 de 1999 "Por medio de la cual se aprueba la "Convención sobre la prohibición del desarrollo, la producción, el almacenamiento y el empleo de armas químicas y sobre su destrucción”, hecho en París el trece (13) de enero de mil novecientos noventa y tres (1993)"”. Sentencia C-328 de 2000. Disponible en http://www.corteconstitucional.gov.co/relatoria/2000/C-328-00.htm [Fecha de visita 14 de mayo de 2014] p. 18. En igual sentido, Corte Constitucional. 24 de enero de 2001. "Demanda de inconstitucionalidad contra el artículo 8 (parcial) de la Ley 418 de 1997". Sentencia C-048 de 2001. Disponible en http://www.corteconstitucional.gov.co/ relatoria/2001/C-048-01.htm [Fecha de consulta 14 de mayo de 2014] p. 27.

72 Karam Quiñones, Carlos (2005): "Acerca del origen y la protección del derecho al medio ambiente”. En Cienfuegos Salgado, David. López Olvera, Miguel Alejandro (Coordinadores). Estudios en homenaje a don Jorge Fernández Ruiz. Disponible en http://biblio.juridicas.unam.mx/libros/4/1627/18.pdf consultado 3/10/2013. (311-342). México: Universidad Nacional Autónoma de México. 
El reconocimiento de la Paz como derecho colectivo, se da partir de la consideración según la cual esta, junto con la seguridad pública, el esclarecimiento de la verdad y el logro de la justicia, constituyen elementos comunes susceptibles de ser reclamados por cualquier sujeto lo cual habilita para que pueda intervenir en su reclamación o defensa ${ }^{73}$.

Lo anterior conlleva a afirmar que, siempre que se den situaciones que afecten la Paz a partir de la vulneración de otros derechos como la verdad, la justicia y la seguridad pública, es jurídicamente posible el uso de las diversas herramientas que provee el ordenamiento jurídico para su defensa.

\subsection{4) La Paz como derecho fundamental o subjetivo}

La Paz también puede ser vista como derecho fundamental. Según se dijo al comienzo de este documento, desde el criterio de la ubicación y por el plus para su reforma, el Artículo 22, contentivo del derecho a la Paz es, sin duda alguna, un derecho fundamental.

Sin embargo, tal consideración encierra una situación sumamente compleja de aspectos sin resolver a partir de la teoría de los derechos fundamentales. Digámoslo de la siguiente manera: jsi un derecho subjetivo se caracteriza por la existencia de (i) una norma jurídica, (ii) una obligación jurídica y de (iii) una posición jurídica ${ }^{74}$, cuáles son los elementos que componen cada una de estas características? Tan difíciles preguntas, casi imposibles de responder por la ausencia de consensos, actúan contra la tesis de la Paz como derecho subjetivo o fundamental. Ni siquiera vien-

73 Conte Constitucional. 28 de junio de 2005. "Proceso de revisión del fallo de tutela proferido por la Sala de Casación Penal de la Corte Suprema de Justicia, en relación con la acción tutelar impetrada por la Asociación para la Promoción Social Alternativa Minga, contra el Fiscal Delegado de la Unidad de los Derechos Humanos de la Fiscalía General de la Nación y el Fiscal 42 Delegado ante el Tribunal Superior de Bogotá”. Sentencia T-589 de 2005. Disponible en http://www.corteconstitucional.gov.co/relatoria/2005/T-589-05. htm [Fecha de consulta 14 de mayo de 2014] p. 38. En el marco de este pronunciamiento, la Corte avaló la intervención de un "actor civil popular" como parte civil dentro de un proceso penal para la garantía del interés jurídico colectivo, frente a "los graves atentados contra los derechos humanos y el derecho internacional humanitario o aquellas conductas que comprometan gravemente la paz o el uso racional de la fuerza militar". En el mismo sentido véase Corte Constitucional. 3 de abril de 2002. "Demanda de inconstitucionalidad contra el artículo 137 de la Ley 600 de 2000, "(p)or la cual se expide el Código de Procedimiento Penal"”. Sentencia C-228 de 2002. Disponible en: http://www.corteconstitucional.gov.co/relatoria/2002/C-228-02.htm [Fecha de consulta 14 de mayo de 2014] p. 32 y Corte Constitucional. 21 de marzo de 2003. "Proceso de revisión del fallo dictado por la Sala de Casación Penal de la Corte Suprema de Justicia, en el trámite de la acción de tutela instaurada por Javier Giraldo Moreno en contra del Fiscal General de la Nación”. Sentencia T-249 de 2003. Disponible en: http://www.corteconstitucional.gov.co/ relatoria/2003/T-249-03.htm [Fecha de consulta 14 de mayo de 2014] p. 22.

74 Arango Rivadeneira, Rodolfo (2005) El concepto de derechos sociales fundamentales. Bogotá: Legis, 380 pp., p. 9. 
do el derecho fundamental como un todo podríamos descifrar tan compleja estructura ${ }^{75}$.

La Corte Constitucional colombiana, evadiendo un poco la discusión sobre los elementos anteriores, en ocasiones ha descartado la naturaleza de derecho fundamental de la $\mathrm{Paz}^{76}$, y en otras, simplemente ha establecido que de su efectividad depende la realización de otros derechos ${ }^{77}$, con lo cual no solo no resuelve las dudas sobre su alcance hermenéutico sino que además traslada la discusión hacia cuál es el entorno social que mejor encarna este concepto y que se presentaron líneas atrás como expresión estado ideal (i) y protocolo de actuación en medio del conflicto (ii).

\subsection{5) La Paz como deber ciudadano o constitucional}

Finalmente, la $\mathrm{Paz}$ se mira como un deber constitucional. En este caso, no estamos hablando de la obligación general de respetar la CP contenida en el Art. $4^{\circ}$ según el cual "Es deber de los nacionales y de los extranjeros acatar la Constitución" ni de lo previsto en el Art. 60 donde reza que "Los particulares solo son responsables por infringir la Constitución (...). Los servidores por la misma causa"78.

Las anteriores afirmaciones, que en puridad solo contienen el deber de someterse a la CP, sirven para reafirmar la inclusión de esta en el ordenamiento jurídico, su especial valor y su carácter de norma de aplicación directa pero no para acercarnos a una dogmática de la Paz como deber.

75 Sobre la teoría del derecho fundamental como un todo véase Alexy, Robert (1993) Teoría de los derechos fundamentales. Traducción de Ernesto Garzón Valdés. Madrid: Centro de Estudios Constitucionales de Madrid, 607 pp. Una explicación de la posición de Alexy la encontramos en Borowski quien nos dice que los derechos fundamentales se pueden ver desde tres clases de posiciones jurídicas básicas: primero, los derechos a algo; segundo, las libertades; tercero, las competencias. Los derechos a algo, distinguidos con la fórmula $R a b G$, implican la existencia de un operador jurídico $(R)$, un titular del derecho $(a)$, un destinatario del derecho (b) y un objeto del derecho $(G)$. En el caso de los derechos como libertades, cuya estructura es $L a b G$, existe un operador jurídico $(L)$, un titular de la libertad (a), un obstáculo para la libertad $(b)$ y la conducta que debe ser omitida o emprendida $(G)$. Finalmente, en el caso de las competencias, que pueden ser en derecho público o privado, se trata de posibilidades de exigir un derecho a algo, por lo que esta categoría pasa a un segundo plano. Véase Borowski, Martín (2003) La estructura de los derechos fundamentales. Traducción de Carlos Bernal Pulido. Bogotá: Universidad Externado de Colombia, 246 pp., p. 24-26.

76 Corte Constitucional. 16 de febrero de 1995. "Demanda de inconstitucionalidad contra la Ley 104 de 1993”. Sentencia C-055 de 1995. Disponible en http://www.corteconstitucional.gov.co/relatoria/1995/C-055-95.htm [Fecha de consulta 14 de mayo de 2014] p. 70.

77 Corte Constitucional. 2 de julio de 1992. "Proceso de tutela T-1088 adelantado por el señor Luis Humberto Rolon Maldonado contra las Fuerzas Militares de Colombia y los Organismos de Seguridad del Estado con sede en el Departamento de Norte de Santander". Sentencia T-439 de 1992. Disponible en http://www.corteconstitucional.gov.co/ relatoria/1992/T-439-92.htm [Fecha de visita 14 de mayo de 2014] p. 10.

78 Disponible en: http://www.secretariasenado.gov.co/senado/basedoc/constitucion_politica_1991.html\#6 
Este primer deber constitucional es el fundamento genérico de la concepción de la Paz como deber pero no es, en estricto sentido, contentivo del significado que pretendemos señalar. Tampoco estamos haciendo alusión al deber correlativo implícito en cada derecho subjetivo: la enunciación de un derecho conlleva el deber negativo de no obstaculizar su ejercicio. Si bien es cierto, el deber de sujeción a la CP conlleva el mandato genérico de respeto por todos sus valores y principios, esto es, el deber negativo de no vulneración, para el tema que nos ocupa existen unas prescripciones específicas que merecen ser analizadas por separado.

En la CP de 1991, el tema de los deberes constitucionales pasa por dos criterios, uno estricto y uno amplio. En sentido amplio, serían deberes todas las obligaciones previstas en la $\mathrm{CP}$, al margen de su contenido o ubicación. Por ejemplo, el deber de todo servidor público de declarar el monto de sus bienes ${ }^{79}$, el deber de respetar el mérito en la carrera administrativa ${ }^{80}$, el deber de asistir cuando fuere citado por alguna Cámara o Comisión del Congreso ${ }^{81}$, entre otros. En sentido estricto, y a falta de una ordenación clara de la CP, serían aquellos que expresamente reciben esa denominación. No aludimos, se aclara, a la obligación correlativa del derecho, sino a los que de manera directa son así denominados, como en el caso del Art. 25 sobre derecho al trabajo que expresamente dice que " $E l$ trabajo es un derecho y una obligación..." o el derecho a la Paz en cuyo Art. 22 se dijo que "La paz es un derecho y un deber de obligatorio cumplimiento" que, como generalmente ocurre con todos los enunciados que con-

79 Dice el Artículo 122 de la CP lo siguiente: "ARTÍCULO 122. No habrá empleo público que no tenga funciones detalladas en ley o reglamento y para proveer los de carácter remunerado se requiere que estén contemplados en la respectiva planta y previstos sus emolumentos en el presupuesto correspondiente. (...). Antes de tomar posesión del cargo, al retirarse del mismo o cuando autoridad competente se lo solicite deberá declarar, bajo juramento, el monto de sus bienes y rentas". Disponible en: http://www.secretariasenado.gov.co/senado/basedoc/constitucion_politica_1991_pr004.html\#122

$80 \quad$ Dice el Artículo 125 lo siguiente: "ARTÍCULO 125. Los empleos en los órganos y entidades del Estado son de carrera. Se exceptúan los de elección popular, los de libre nombramiento y remoción, los de trabajadores oficiales y los demás que determine la ley. Los funcionarios, cuyo sistema de nombramiento no haya sido determinado por la Constitución o la ley, serán nombrados por concurso público. El ingreso a los cargos de carrera y el ascenso en los mismos, se harán previo cumplimiento de los requisitos y condiciones que fije la ley para determinar los méritos y calidades de los aspirantes". Disponible en: http://www.secretariasenado.gov.co/senado/basedoc/ constitucion_politica_1991_pr004.html\#125

81 Dice el Artículo 137 lo siguiente: "ARTÍCULO 137. Cualquier comisión permanente podrá emplazar a toda persona natural o jurídica, para que en sesión especial rinda declaraciones orales o escritas, que podrán exigirse bajo juramento, sobre hechos relacionados directamente con las indagaciones que la comisión adelante. Si quienes hayan sido citados se excusaren de asistir y la comisión insistiere en llamarlos, la Corte Constitucional, despues de oirlos, resolverá sobre el particular en un plazo de diez días, bajo estricta reserva. La renuencia de los citados a comparecer o a rendir las declaraciones requeridas, será sancionada por la comisión con la pena que señalen las normas vigentes para los casos de desacato a las autoridades". Disponible en: http://www.secretariasenado.gov.co/senado/basedoc/constitucion_politica_1991_pr004.html\#137 
tienen deberes constitucionales, carecen de sanción por su inobservancia estando en cabeza del Legislador la obligación de regular los supuestos específicos del deber y de establecer las sanciones por su incumplimiento ${ }^{82}$.

En este sentido, y para efectos de nuestro análisis, vamos a partir de la posición de Díaz ${ }^{83}$ para quien por deber constitucional, podemos entender "todas las conductas o actuaciones que la Constitución impone o dirige formalmente a los individuos o a los ciudadanos".

Sin embargo, dos conclusiones se imponen en torno a la fuerza vinculante de los deberes: en primer lugar, su sola consagración no genera ninguna obligación específica para los ciudadanos y, en segundo lugar, si bien están dirigidos más a los órganos del poder público que a los particulares, constituyen "meras habilitaciones" toda vez que ni siquiera frente a estos existe alguna sanción por su inobservancia ${ }^{84}$.

Con este marco teórico, podemos decir que los deberes constitucionales, enunciados en el Art. 95 de la CP de 1991, son restricciones a la libertad personal, necesarias para la existencia misma del Estado que son exigibles directamente cuando a partir de su desconocimiento se lesionan derechos fundamentales, de lo contrario, se requiere de expresa regulación legal ${ }^{85}$.

En el tema preciso de su exigibilidad, tiene dicho la jurisprudencia que los mismos deben ser compatibles con el ejercicio de los derechos constitucionales. Así, y aun cuando la $\mathrm{CP}$ asigna distintos deberes a los ciudadanos (Arts. 6º 49 y 95), estos no pueden afectar el núcleo esencial

82 Díaz Revorio, Francisco (2011) "Derechos humanos y deberes fundamentales. Sobre el concepto de deber constitucional y los deberes en la Constitución Española de 1978”. IUS. Revista del Instituto de Ciencias Juridicas de Puebla A.C., Vol. 5, No. 28, diciembre, pp. 278310. Disponible en: http://www.redalyc.org/articulo.oa?id=293222189013 [Fecha de consulta 22 de enero de 2014], p. 287-288.

83 Díaz Revorio (2011) 286-287.

84 Díaz Revorio (2011) 288.

85 Corte Constitucional. 14 de marzo de 1994. "Proceso de tutela T-23703 adelantado por Mario Jaramillo Valencia, en representación de Ernesto Julio Osorio, Contra Carlos Ernesto Osorio Agudelo". Sentencia T-125 de 1994. Disponible en http://www.corteconstitucional.gov.co/relatoria/1994/T-125-94.htm [Fecha de consulta 14 de mayo de 2014] p. 14. En el mismo sentido, Corte Constitucional. 8 de febrero de 1995 . "Proceso de tutela T-45125, interpuesto por Ismael Simijaca y Dulcelina Pineda de Malagón en contra de Elver García Camacho". Sentencia T-036 de 1995. Disponible en: http://www. corteconstitucional.gov.co/relatoria/1995/T-036-95.htm [Fecha de visita 14 de mayo de 2014] p. 7. Corte Constitucional. 19 de febrero de 1996. "Proceso de tutela número T- 84047 promovido por María Elvia Benavides de Chávez contra Luis Idelfonso Chávez.”. Sentencia T-602, 1996. Disponible en: http://www.corteconstitucional.gov.co/ relatoria/1996/T-062-96.htm [Fecha de consulta 14 de mayo de 2014] p. 9; Corte ConsTitucional. 9 de abril de 2002. "Demanda de inconstitucionalidad contra el numeral 6 del artículo 6 de la Ley 25 de 1992”. Sentencia C-246 de 2002. Disponible en: http://www. corteconstitucional.gov.co/relatoria/2002/C-246-02.htm [Fecha de consulta 14 de mayo de 2014] p. 10. 
de los derechos ${ }^{86}$ ni convertirse en negación de los mismos, por cuanto esto implicaría una trampa a la libertad ${ }^{87}$.

En el tema que se analiza, expresa el Núm. $6^{\circ}$ del Art. 95 lo siguiente: "Art. 95.- (...) Son deberes de la persona y del ciudadano: (...) 6. Propender al logro y mantenimiento de la paz"88.

La concreción del deber de la Paz, indiscutiblemente debe pasar por una discusión democrática -entiéndase legislativa-, que señale las obligaciones precisas que de este se derivan.

A título de ejemplo, (i) la prestación del servicio militar, (ii) el financiamiento de la defensa y seguridad ciudadanas, (iii) la obligación de colaborar en la investigación y judicialización de los delitos atroces o que involucran amplios sectores sociales, (iv) el apoyo a medidas adoptadas para la superación del conflicto armado - piénsese en la posibilidad de desgravaciones tributarias a quienes vinculen personal que se haya desmovilizado de los grupos armados al margen de la ley-, (v) las sanciones ante actos discriminatorios o segregacionistas que puedan llevar al surgimiento de conflictos o impedir la superación de estos ${ }^{89}$, entre otras medidas, son expresiones de lo que, democráticamente, se puede desprender de la Paz como deber y que, se reitera, pasa por el tamiz del Legislador, en estricta ponderación con los derechos constitucionales.

\section{3) Criterios de Determinación del peso abstraCto de los DIFERENTES CONCEPTOS DE PAZ EN LA CP DE 1991}

Finalmente, para acercarnos al concepto de Paz en la CP de 1991, sin decir con ello que la adscripción a un concepto signifique la negación del otro o que asumamos criterios absolutos, recurriremos a algunos de

86 Corte Constitucional. 17 de abril de 1997. "Acciones de tutela instauradas por Yaneth Rubiano Labro y otros, en representación de sus hijos, soldados bachilleres, contra los comandantes del Ejército Nacional y de la Segunda Brigada, y contra el Teniente Coronel José Elías Mahecha Cárdenas". Sentencia SU-200 de 1997. Disponible en: http://www. corteconstitucional.gov.co/relatoria/1997/SU200-97.htm [Fecha de consulta 14 de mayo de 2014] p. 13.

87 Corte Constitucional. 16 de noviembre de 1994. "Acciones de inconstitucionalidad contra los artículos 4o. (parcial), 9 (parcial), 10, 11, 13 (parcial), 14, 36, 37, 41 (parcial), 42, 49 (parcial), 55 (parcial) y 57 de la Ley 48 de 1993, "por la cual se reglamenta el servicio de Reclutamiento y Movilización"”. Sentencia C-511 de 1994. Disponible en: http://www. corteconstitucional.gov.co/relatoria/1994/C-511-94.htm [Fecha de consulta 14 de mayo de 2014] p. 23.

88 Disponible en: http://www.secretariasenado.gov.co/senado/basedoc/constitucion_politica_1991_pr002.html\#95

89 Por ejemplo, el delito de racismo o discriminación en el Art. 3o de la Ley 1482 de 2011, "Por medio de la cual se modifica el Código Penal y se establecen otras disposiciones". Disponible en: www.bibliotecajuridica.com.co/LEY_1482_DE_2011.pdf 
los criterios que la doctrina ${ }^{90}$ utiliza en la determinación del peso abstracto de los principios en el ejercicio de ponderación para significar que, sin asumir prima facie la existencia de una jerarquía formal de las ideas en colisión, es posible reconocer una importancia material distinta en cada caso dependiendo del valor que se les asigna en la práctica constitucional ${ }^{91}$. Esta estrategia parte de la base que la existencia de un orden duro entre contenidos constitucionales, determinado por el solo peso abstracto es insuficiente para generar una regla de precedencia pero que, como criterio adicional, puede despejar muchas de las dudas que una propuesta de esta naturaleza genera ${ }^{92}$.

En primer lugar, tenemos el criterio de la jerarquía constitucional de los principios, para el caso, de los postulados constitucionales. Según este criterio, es posible que en tanto mayor sea el reconocimiento del postulado en las fuentes del derecho, más cerca se encuentre de recibir un mayor peso ${ }^{93}$. En tal sentido, si el fundamento es del orden constitucional estaremos ante elementos de primer grado mientras que si carecen de respaldo constitucional directo serán de segundo grado, partiendo así de la distinción entre lo constitucionalmente necesario y lo constitucionalmente posible ${ }^{94}$. En el presente caso, estamos ante postulados que tienen sustento constitucional por lo que este criterio no nos proporciona elementos de juicio. Sin embargo, la existencia de reformas constitucionales que se fundamentan en uno de estos postulados, esto es, es una mayor repetición del postulado dentro de la CP se traduce en un mayor reconocimiento dentro de la CP como fuente del derecho y, por ende, en la aceptación de una mayor jerarquía constitucional. Así, por ejemplo, mediante Acto Legislativo 01 de $2012^{95}$ se establecieron mecanismos de justicia transicional en el marco del Artículo 22 constitucional, es decir, de la Paz como principio de carácter individual. Aunque en la norma se habla de la consecución de la Paz como propósito de la reforma, se ligan una serie de deberes y de garantías como la verdad, la justicia y la reparación a la consecución de ese estado ideal.

En segundo lugar, tenemos el criterio según el cual los principios individuales tienen prioridad frente a los principios colectivos. En el caso de la CP de 1991, que acoge esas raíces liberales que declararon los derechos fundamentales como barreras de contención al poder del Estado y a la opinión de las mayorías (Art. $1^{\circ} \mathrm{CP}$ ) y que, si bien consagra el principio

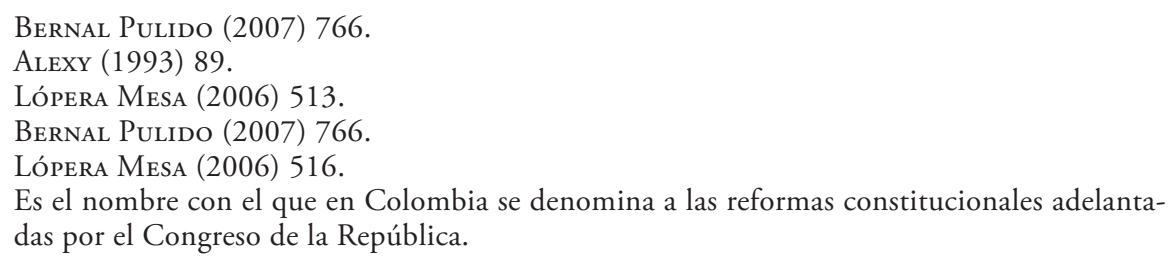


de que el interés general prevalece sobre el particular, entiende que este debe ser matizado en tanto siempre se debe tener en cuenta "al otro" 96 , resulta claro que el postulado de carácter individual, si encarna un derecho fundamental, tendrá una prevalencia prima facie frente al colectivo, lo que obliga a una justificación superior si se pretende optar por esta segunda opción.

En el caso de la Paz, se reconoce que esta es un derecho, esto es, un principio, tanto de carácter individual como de carácter colectivo. Asimismo tiene la connotación de valor que propende por un estado ideal. Si se quisiera ponderar enfrentando el valor con el principio, se podría optar por la vía de considerarlo principio, o mejor aún, de reconocer que la naturaleza de principio ostenta un mayor peso frente a una posible naturaleza de valor, con lo cual las garantías del primero primarían sobre las del segundo. El problema estaría en la ponderación interna entre derecho fundamental y derecho colectivo. En este caso, se podría decir que, prima facie, habría lugar a reconocer que las garantías que conlleva como derecho fundamental subjetivo tendrían un mayor peso abstracto frente a las que constituyen derecho colectivo. Sin embargo, se parte en esta hipótesis de una falacia y es la de considerar la Paz como derecho fundamental. La propia Corte Constitucional ha desechado tal naturaleza ${ }^{97}$ y ha considerado que la inclusión de muchos derechos como fundamentales se debió a la ausencia de aprobación por parte de la Asamblea Nacional Constituyente de la ordenación de los artículos dentro de la $\mathrm{CP}^{98}$.

Frente a esta hipótesis, se habría de considerar que la Paz es un principio, de naturaleza colectiva y circunstancialmente de naturaleza fundamental, con lo cual el reconocimiento del mayor peso depende de si la circunstancia específica se traduce en violación directa de un derecho fundamental (criterio de la conexidad) caso en el cual las garantías de los otros derechos darían ese mayor peso en la ponderación, en caso contra-

96 Conte Constitucional. 26 de marzo de 2012. "Acción de Tutela instaurada por Alba Luz Marrugo Mestra, Neiver Alexander Gordón Romero y Héctor Eliécer Cumplido Barbudo contra la Alcaldía Distrital de Cartagena de Indias -Secretaría de Infraestructura-, el Consorcio Cartagena 2010 y Transcaribe". Sentencia T-244 de 2012. Disponible en: http:// www.corteconstitucional.gov.co/relatoria/2012/T-244-12.htm [Fecha de consulta 14 de mayo de 2014] p. 26.

97 Corte Constitucional. 16 de febrero de 1995. "Demanda de inconstitucionalidad contra la Ley 104 de 1993”. Sentencia C-055 de 1995. Disponible en http://www.corteconstitucional.gov.co/relatoria/1995/C-055-95.htm [Fecha de consulta 14 de mayo de 2014] p. 81.

98 Véase Cepeda Espinosa, Manuel José (1993) La Constituyente por dentro. Bogotá: Presidencia de la República. Consejería para el desarrollo de la Constitución, 331 pp., p. 1, li. En el mismo sentido Corte Constitucional. 8 de mayo de 1992. "Proceso de tutela, identificado con el número de radicación T-644, adelantada por Pastora Emilia Upegui Noreña”. Sentencia T-002 de 1992. Disponible en: http://www.corteconstitucional.gov.co/ relatoria/1992/T-002-92.htm [Fecha de consulta 14 de mayo de 2014] p. 10. 
rio, se habría de ver como derecho colectivo con las implicaciones que esto acarre.

En tercer lugar, la prioridad en función del grado de resistencia constitucional. Conforme a este criterio, se otorgaría un mayor peso al postulado que cuente (i) con mayores y más eficaces medidas judiciales de protección, (ii) que estén sometidos a reserva de ley especial, (iii) cuya regulación legislativa exija de mayorías cualificadas, (iv) que posean un plus para su reforma constitucional o (v) que sean de aplicación inmediata aun ante la ausencia de regulación legislativa.

En el caso de la Paz, la CP de 1991 como prácticamente todas las constituciones occidentales, carece de mecanismos judiciales de protección de los valores constitucionales. De entrada, los valores tienen función creativa e interpretativa, las cuales están dirigidas al Legislador la primera y al juzgador la segunda, pero esta última solo sirve como criterio de orientación. La función integradora de los valores está limitada a hipótesis en las cuales este se acompaña de un principio o se aplican a la luz de una interpretación global de los hechos y del derecho y no como normas de aplicación inmediata ${ }^{99}$. Por esta razón, se desecha la posibilidad de ponderar la Paz como valor y como principio en función de este criterio. En segundo lugar, tenemos que los valores se pueden desarrollar por el Legislador -ordinario o extraordinario- a través del tipo de norma que prefieran, salvo que, por el tema a través del cual lo reglamenten, tenga un trámite especial. En el caso de los principios, si se miran como colectivos, correspondería a una ley ordinaria y si se acogen como fundamentales (bien de manera directa o por su conexidad con otra garantía menos compleja), correspondería a una ley estatutaria (Art. 152-a de la CP). Para el caso colombiano, el Acto Legislativo 01 de 2013 prevé que una ley estatutaria será la encargada de reglamentar lo previsto en este y que responde a la idea de la Paz como derecho fundamental. La tercera regla es la de que su regulación esté sujeta a mayorías cualificadas. Al igual que en lo anterior, la CP prevé mayorías especiales para las leyes orgánicas (Art. 151) y estatutarias (Art. 152) las cuales están restringidas a ciertos temas. En principio, por tratarse de un derecho fundamental correspondería a Ley Estatutaria, mientras que en el caso de los valores, cualquier tipo de ley, incluyendo la ordinaria (Art. 150) lo podría materializar. La cuarta regla es la de que exista un plus para su reforma. En el caso de la CP de 1991, el Art. 377 prevé la posibilidad de un referendo derogatorio cuando haya una reforma constitucional que recaiga sobre los derechos conte-

99 Corte Constitucional. 5 de junio de 1992. "Proceso de acción de tutela promovido por el señor José Manuel Rodríguez Rangel contra el señor Enrique Chartuny González, gerente de las Empresas Públicas de Cartagena". Sentencia T-406 de 1992. Disponible en http:// www.corteconstitucional.gov.co/relatoria/1992/T-406-92.htm [Fecha de visita 14 de mayo de 2014] p. 11. 
nidos en el Capítulo I del Título II, es decir, los artículos 11 a 41, con lo que esta regla converge en el mayor peso al principio. La quinta y última regla es que se pueden aplicar directamente aun sin mediar regulación intermedia. En el caso de los valores, salvo la extraña hipótesis de aplicación de un valor a la luz de una visión global de los hechos y del derecho o acompańados de un principio tal y como lo aceptó la Corte Constitucional ${ }^{100}$, los valores no tendrían aplicación directa como sí la tienen los principios.

En cuarto lugar, la cercanía de posición afectada o protegida con el contenido esencial del postulado. Según este criterio, se daría un mayor peso al postulado cuyas garantías esenciales, aquellas sin las cuales desaparece o se transforma en otro, se ponen en riesgo con la intervención ${ }^{101}$. Para el caso en cuestión, cuando se enfrente la Paz, en cualquiera de sus expresiones, con alguna intervención legislativa o judicial, se dará prioridad al postulado cuyas garantías esenciales o cuyo contenido fundamental se encuentre en más grave riesgo no siendo posible en este momento hacer ningún tipo de especulación al respecto.

En quinto lugar, la vinculación con el principio democrático y de la dignidad humana. La aceptación particular de estos dos principios tiene la siguiente explicación: mientras que el principio de la dignidad humana sirve como soporte axiológico del marco de derechos de la CP, el principio democrático legitima colectivamente las decisiones que se adopten. En el derecho europeo, la aplicación de esta regla tiene amplia aceptación $^{102}$. En el caso colombiano, la CP de 1991 establece que Colombia es un Estado democrático, fundado en el respeto de la dignidad humana (Art. $1^{\circ}$ ), teniendo estas normas, precisamente, la connotación de principios, a la par que el Preámbulo, el cual goza de fuerza vinculante ${ }^{103}$ fundamenta la Constitución en el valor democrático.

Conforme a lo anterior, la Paz está ligada tanto con el valor democrático como con los principios democrático y de dignidad humana, lo que acerca el concepto de Paz más a la idea de principio que a la de valor.

Finalmente, en sexto lugar, tenemos el reconocimiento de prioridad en función de los precedentes. En este caso, entre mayor sea el número

100 Corte Constitucional. 5 de junio de 1992. "Proceso de acción de tutela promovido por el señor José Manuel Rodríguez Rangel contra el señor Enrique Chartuny González, gerente de las Empresas Públicas de Cartagena”. Sentencia T-406 de 1992. Disponible en http:// www.corteconstitucional.gov.co/relatoria/1992/T-406-92.htm [Fecha de visita 14 de mayo de 2014] p. 11

101 Lópera Mesa (2006) 520.

102 Bernal Pulido (2007) 768, Lópera Mesa (2006) 523.

103 Corte Constitucional. 13 de agosto de 1992. "Demandas de inconstitucionalidad acumuladas contra el artículo $2^{\circ}$ de la ley 60 de 1990 y el Decreto Ley 1660 de 1991". Sentencia SC-479 de 1992. Disponible en http://www.corteconstitucional.gov.co/ relatoria/1992/C-479-92.htm [Fecha de visita 14 de mayo de 2014] p. 28. 
de veces que ese criterio ha sido reconocido en precedentes constitucionales mayor será el peso que se le asigne. Así, a partir de las funciones de estabilización, progreso y descarga que se satisfacen con el uso del precedente ${ }^{104}$, se concilia la pretensión de universalidad de la dimensión autoritativa del derecho con la seguridad jurídica que el respeto al precedente significa ${ }^{105}$.

Para el caso colombiano, existe una gran cantidad de precedentes que hacen uso de la Paz y en otro sentido. Por eso, en la siguiente relación se intenta señalar a partir de un rastreo pormenorizado los pronunciamientos judiciales en el que expresamente se recurrió a concepto de la Paz sin perjuicio que en un mismo pronunciamiento se le haya reconocido una doble condición. Estos pronunciamientos fueron expresamente referenciados en el presente artículo y por eso serán tenidos en cuenta para efectos del fin propuesto. Así, frente a la idea de la Paz como valor, bien como ausencia de guerra o como ausencia de conflicto, esto es, como estado ideal, acuden aproximadamente quince (15) precedentes ${ }^{106}$; sobre la idea de la Paz como principio, bien como derecho fundamental, colectivo o como protocolo de actuación en medio del conflicto existen aproximadamente catorce (14) precedentes ${ }^{107}$; finalmente, se le mira como un deber en seis (6) precedentes ${ }^{108}$.

104 Alexy, Robert (1997) Teoría de la argumentación jurídica. Traducción de Manuel Atienza e Isabel Espejo. Madrid: Centro de Estudios Constitucionales de Madrid, 346 pp., p. 264.

105 Lópera Mesa (2006) 524.

106 Véase Corte Constitucional. Sentencia C-353, 1994; Corte Constitucional. Sentencia C-045, 1996; Corte Constitucional. Sentencia C-339 de 1998; Corte Constitucional. Sentencia C-340 de 1998; Corte Constitucional. Sentencia C-328 de 2000; Corte Constitucional. Sentencia C-991 de 2000; Corte Constitucional. Sentencia C-048 de 2001; Corte Constitucional. Sentencia C-695 de 2002; Corte Constitucional. Sentencia C-644 de 2004; Corte Constitucional. Sentencia C-928 de 2005; Corte Constitucional. Sentencia C-367 de 2006; Corte Constitucional. Sentencia C-370 de 2006; Corte Constitucional. Sentencia T-1025 de 2007; Corte Constitucional. Sentencia C-333 de 2012, Corte Constitucional. Sentencia C-579 de 2013.

107 Véase Corte Constitucional. Sentencia T-008 de 1992; Corte Constitucional. Sentencia T-102 de 1993; Corte Constitucional. Sentencia C-225 de 1995; Corte Constitucional. Sentencia C-290 de 1995; Corte Constitucional. Sentencia C-045 de 1996; Corte Constitucional. Sentencia C-328 de 2000; Corte Constitucional. Sentencia C-991 de 2000; Corte Constitucional. Sentencia C-0 48 de 2001; Corte Constitucional. Sentencia C-578 de 2002; Corte Constitucional. Sentencia C-689 de 2002; Corte Constitucional. Sentencia T-249 de 2003; Corte Constitucional. Sentencia T-598 de 2005; Corte Constitucional. Sentencia C-928 de 2005; Corte Constitucional. Sentencia C-370 de 2006

108 Véase Corte Constitucional. Sentencia T-102 de 1993; Corte Constitucional. Sentencia C-045 de 1996; Corte Constitucional. Sentencia C-991 de 2000; Corte Constitucional. Sentencia C-0 48 de 2001; Corte Constitucional. Sentencia C-578 de 2002; Corte Constitucional. Sentencia C-370 de 2006. 


\section{CONCLUSIONES}

Se plantean las siguientes conclusiones:

En primer lugar, pese a su enunciación en el Art. 22 de la CP, la Paz no es un derecho fundamental autónomo, porque ni su estructura hermenéutica lo permite ni la jurisprudencia de la Corte Constitucional le ha utilizado en dicho sentido.

En segundo lugar, el mayor peso que ostente una consideración hermenéutica sobre la paz (valor, principio, deber), no significa, per se, que estén excluidas las demás consideraciones. En tal sentido, su naturaleza particular dependerá de las condiciones en juego.

En tercer lugar, según las reglas de asignación de peso abstracto la Paz es, prima facie, un principio dirigido a los órganos del poder público, cuyo contenido hermenéutico es el de evitar toda clase de conflicto y salir de este cuando ya se ha presentado.

En cuarto lugar, el alcance de la Paz como valor, es idéntico al de la Paz como principio, en tal sentido, el uno conduce indefectiblemente al otro.

\section{BIBLIOGRAFÍA}

- Alexy, Robert (1993) Teoría de los derechos fundamentales. Traducción de Ernesto Garzón Valdés. Madrid: Centro de Estudios Constitucionales de Madrid, 607 pp.

- Alexy, Robert (1997) Teoría de la argumentación juridica. Traducción de Manuel Atienza e Isabel Espejo. Madrid: Centro de Estudios Constitucionales de Madrid, 346 pp.

- Angulo Bossa, Jaime (2002) El Preámbulo de la Constitución Nacional. 2a ed. Bogotá: Temis. 541 pp.

- Arango Rivadeneira, Rodolfo (2005) El concepto de derechos sociales fundamentales. Bogotá: Legis, 380 pp.

- Aristóteles (1967) La Politica. Versión de Natividad Massanés. 4 Edición. Barcelona: Editorial Iberia S.A., 306 pp.

- Bernal Pulido, Carlos (2007) El principio de proporcionalidad y los derechos fundamentales. $3^{\mathrm{a}}$ ed. Madrid: Centro de Estudios Políticos y Constitucionales, 883 pp.

- Bernal Pulido, Carlos (2005) El derecho de los derechos. Bogotá: Universidad Externado de Colombia, 419 pp.

- Boвbio, Norberto (1981) El problema de la guerra y las vías de la paz. Traducción de Jorge Binaghi. Barcelona: Gedisa editorial, 204 pp.

- Borowski, Martín (2003) La estructura de los derechos fundamentales. Traducción de Carlos Bernal Pulido. Bogotá: Universidad Externado de Colombia, 246. pp. 
- Camargo, Pedro Pablo (1999) Las acciones populares y de grupo. Bogotá: Leyer, 333 pp.

- Cepeda Espinosa, Manuel José (1993) La Constituyente por dentro. Bogotá: Presidencia de la República. Consejería para el desarrollo de la Constitución, 331 pp.

- Díaz Revorio, Francisco (2011) "Derechos humanos y deberes fundamentales. Sobre el concepto de deber constitucional y los deberes en la Constitución Española de 1978." IUS. Revista del Instituto de Ciencias Jurídicas de Puebla A.C., Vol. 5, No. 28, diciembre, 278-310. Disponible en: http://www.redalyc.org/articulo. oa?id=293222189013 [Fecha de consulta 22 de enero de 2014]

- Dueñas Ruiz, Óscar José (2005) Acción y procedimiento en la tutela. 4a ed. Bogotá: Ediciones Librería del Profesional. 595 pp.

- Estrada Vélez, Sergio Iván (2006) Los principios jurídicos y el bloque de constitucionalidad. Medellín: Universidad de Medellín, 152 pp.

- Ferrater Mora, José (1965) Diccionario de filosofía. Tomo II. Buenos Aires: Sudamericana, 1005 pp.

- Gadamer, Hans-Georg (1998) Verdad y método. Tomo II. 3a edición. Traducción de Manuel Olasagasti. Salamanca: Ediciones Sígueme, 429 pp.

- Gutiérrez Beltrán, Andrés Mauricio (2007) El bloque de constitucionalidad. Concepto y fundamentos. Bogotá: Universidad Externado de Colombia, 94 pp.

- Habermas, Jürgen (1997). "La idea kantiana de paz perpetua. Desde la distancia histórica de doscientos años". Isegoría, no 16, pp. 61-90. Disponible en: isegoria.revistas.csic.es/index.php/isegoria/article/ download/184/184 P[Fecha de visita 15 de mayo de 2014]

- Hoвbes, Thomas (1993) "Leviathan". In Great Books of the Western World. No 21. Chicago: Encyclopaedia Britannica, inc. 43-283 pp.

- Isócrates (1982) Discursos. Traducción de Juan Manuel Guzmán Hermida. Madrid: Biblioteca Gredos. 521. pp.

- Jellinek, Georg (2006) Reforma y mutación de la Constitución. Traducción de Christian Förster. Bogotá: Leyer, 114 pp.

- Karam Quiñones, Carlos (2005): "Acerca del origen y la protección del derecho al medio ambiente". En Cienfuegos Salgado, David. López Olvera, Miguel Alejandro (Coordinadores). Estudios en homenaje a don Jorge Fernández Ruiz. Disponible en http://biblio.juridicas.unam.mx/libros/4/1627/18.pdf consultado 3/10/2013. (311-342). México: Universidad Nacional Autónoma de México.

- Kant, Immanuel (2007) La paz perpetua. Traducción de José Loya Mateos. Madrid: Mestas ediciones, 89 pp. 
- Kelsen, Hans (1943) Derecho y paz en las relaciones internacionales. Traducción de Florencio Acosta. México: Fondo de Cultura Económica, 209 pp.

- Kelsen, Hans (2008) la paz por medio del derecho. Traducción de Luis Echávarri. Madrid: Trotta, 155 pp.

- Latorre Latorre, Virgilio (2012) Bases metodológicas de la investigación jurídica. Valencia: Tirant lo Blanch, 199 pp.

- Lópera Mesa, Gloria Patricia (2006) Principio de proporcionalidad y ley penal. Madrid: Centro de Estudios Políticos y Constitucionales, $661 \mathrm{pp}$.

- López Calera, Nicolás María (1993). "Vivir en Paz: Paz y derechos humanos". Derechos y libertades. Revista del Instituto Bartolomé de las Casas. Año No 1, No 1, pp. 169-178. Disponible en: http://dialnet. unirioja.es/servlet/articulo?codigo $=174981$. [Tomado 12/5/2014].

- López Medina, Diego Eduardo (2007) El derecho de los jueces. 2a ed. Bogotá: Legis, 366 pp.

- Martínez Zorrilla, David (2007) Conflictos constitucionales, ponderación e indeterminación normativa. Madrid: Marcial Pons, 392 pp.

- Machiavelli, Nicoló (1993) “The Prince". In Great Books of the Western World. No 21. Chicago: Encyclopaedia Britannica, inc. 3-37 pp.

- Moreno Millán, Franklin (2002) La jurisprudencia constitucional como fuente del derecho. Bogotá: Leyer. 191 pp.

- Moreno Millán, Franklin (2010) "De los derechos fundamentales en la Constitución de 1991", Revista Aequitas. Universidad Santiago de Cali. Año 1 No $1.55-74$ pp

- Moreno Millán, Franklin (2011) "Fundamentos constitucionales de las relaciones internacionales del Estado colombiano". En AA.VV. Las relaciones internacionales de Colombia, una mirada politica y juridica. Cali. Universidad Santiago de Cali. Cali. 171-188 pp.

- Moreno Millán, Franklin (2013) La acción ciudadana de inconstitucionalidad. Devenir dogmático. Cali: Universidad de San Buenaventura. 109 pp.

- Moro, Tomás (2005). Utopia. Traducción moderna de Guillermo Rovirosa. Disponible en http://www.laeditorialvirtual.com.ar/pages/ Moro_Tomas/TomasMoro_Utopia.htm [Fecha de consulta 3 de octubre de 2013], sin número de páginas.

- Osuna Patiño, Néstor Iván (1998) Tutela y amparo. Derechos protegidos. Bogotá: Universidad Externado de Colombia. 368 pp.

- Platón (1980). "Las leyes". Tomo X. Traducción de Juan David García Bacca. En: Obras Completas. Caracas: Facultad de Humanidades y Educación Universidad Central de Caracas. 1-518 pp. 
- Platón (1980) "La República o el Estado". Tomo VII. Traducción de Juan David García Bacca. En: Obras Completas. Caracas: Facultad de Humanidades y Educación Universidad Central de Caracas. 1-304 pp.

- Estudios en homenaje a don Jorge Fernández Ruiz. Disponible en http://biblio.juridicas.unam.mx/libros/4/1627/18.pdf consultado 3/10/2013. (311-342). En AA.VV. (México. Universidad Nacional Autónoma de México).

- Ramón, Consuelo, De Lucas, Javier (2007) Querela pacis, perpetua? Una reivindicación del Derecho internacional. Valencia: Patrona SudNord, 233 pp.

- Rousseau, Charles (1966) Derecho internacional público profundizado. Traducción de Delia García Daireaux. Buenos Aires: Editorial La Ley, 468 pp.

- Sagües, Néstor (2007) Manual de derecho constitucional. Buenos Aires: Editorial Astrea de Alfredo y Ricardo Depalma. 957 pp.

- Sierra Porto, Humberto Antonio (1998) Concepto y tipos de ley en la Constitución colombiana. Bogotá: Universidad Externado de Colombia, 426 pp.

- Tucídides (1969): "Historia de la guerra del Peloponeso". Traducción, introducción y notas de David González Maeso. En Historiadores Griegos. Madrid: Aguilar S.A., 1265-1546 pp.

- Uprimny Yepes, Rodrigo (2005) "El bloque de constitucionalidad en Colombia. Un análisis jurisprudencial y un ensayo de sistematización doctrinal". Disponible en: http://www.dejusticia.org/ index.php? modo=interna\&tema $=$ sistema_judicial \&publicacion $=72$. [Fecha de consulta 1 de octubre de 2013] pp. 35.

- Valencia Restrepo, Hernán (1999) Nomoárquica, principialística jurídica o de los principios generales del derecho. Bogotá: Temis, 530 pp.

- Varvaroussis, Paris (1996) La idea de la paz. Traducción de Claudia Marcela Restrepo. Bogotá; Temis, 174 pp.

- Verdross, Alfred (1955) Derecho Internacional Público. Traducción de Antonio Truyol y Serra. Madrid: Aguilar, 563 pp.

- Ríos Sierra, Jerónimo; Bula Escobar, Germán; Brocate Pirón, Roberto. "Estado, Estado de Derecho y Violencia Armada en Colombia". Revista de Paz y Conflictos. Disponible en www.ugr.es/.../ Estado_de_derecho_violencia_armada_colombia.html. [Tomado 12/5/2014).

\section{JURISPRUDENCIA CITADA}

- Corte Constitucional. 8 de mayo de 1992. "Proceso de tutela, adelantada por Pastora Emilia Upegui Noreńa”. Sentencia T-002 
de 1992. Disponible en http://www.corteconstitucional.gov.co/ relatoria/1992/T-002-92.htm [fecha de consulta 14 de mayo de 1992] pp. 5-13.

- Corte Constitucional. 18 de mayo de 1992. "Revisión de la sentencia proferida por el Honorable Tribunal Superior del Distrito de Santafé de Bogotá D.C”. Sentencia T-008 de 1992. Disponible en http://www.corteconstitucional.gov.co/relatoria/1992/T-008-92.htm [Fecha de consulta 14 de mayo de 2014] p. 9, 22.

- Corte Constitucional. 5 de junio de 1992. "Proceso de acción de tutela promovido por el señor José Manuel Rodríguez Rangel contra el señor Enrique Chartuny González, gerente de las Empresas Públicas de Cartagena”. Sentencia T-406 de 1992. Disponible en http://www.corteconstitucional.gov.co/relatoria/1992/T-406-92.htm [Fecha de visita 14 de mayo de 2014]. p. 10, 11, 12.

- Corte Constitucional. 2 de julio de 1992. "Proceso de tutela T-1088 adelantado por el señor Luis Humberto Rolon Maldonado contra las Fuerzas Militares de Colombia y los Organismos de Seguridad del Estado con sede en el Departamento de Norte de Santander". Sentencia T-439 de 1992. Disponible en http://www. corteconstitucional.gov.co/relatoria/1992/T-439-92.htm [Fecha de visita 14 de mayo de 2014] p. 10.

- Corte Constitucional. 13 de agosto de 1992. "Demandas de inconstitucionalidad acumuladas contra el artículo $2^{\circ}$ de la ley 60 de 1990 y el Decreto Ley 1660 de 1991". Sentencia SC-479 de 1992. Disponible en http://www.corteconstitucional.gov.co/ relatoria/1992/C-479-92.htm [Fecha de visita 14 de mayo de 2014] pp. 28-32.

- Corte Constitucional. 10 de marzo de 1993. "Revisión de tutela contra la decisión adoptada por el Alcalde Municipal, el Comandante de la Policía y el Ministerio de Defensa, de construir el nuevo Comando de Policía en ese sector del Municipio". Sentencia T-102 de 1993. Disponible en http://www.corteconstitucional.gov. co/relatoria/1993/T-102-93.htm [Fecha de consulta 14 de mayo de 2014] p. 13.

- Corte Constitucional. 14 de marzo de 1994. "Proceso de tutela T-23703 adelantado por Mario Jaramillo Valencia, en representación de Ernesto Julio Osorio, contra Carlos Ernesto Osorio Agudelo". Sentencia T-125 de 1994. Disponible en http:// www.corteconstitucional.gov.co/relatoria/1994/T-125-94.htm [Fecha de consulta 14 de mayo de 2014] p. 14.

- Corte Constitucional. 10 de agosto de 1994. "Revisión Constitucional del proyecto de ley estatutaria No. 214 de 1994 Cámara y 183 de 1994 Senado "Por la cual se expiden algunas disposiciones en materia electoral"”Sentencia C-353 de 1994. 
Disponible en Sentencia C-353 de 1994. Disponible en http://www. corteconstitucional.gov.co/relatoria/1994/C-353-94.htm [Fecha de visita 14 de mayo de 2014].

- Corte Constitucional. 16 de noviembre de 1994. "Acciones de inconstitucionalidad contra los artículos 4o. (parcial), 9 (parcial), 10, 11, 13 (parcial), 14, 36, 37, 41 (parcial), 42, 49 (parcial), 55 (parcial) y 57 de la Ley 48 de 1993, "por la cual se reglamenta el servicio de Reclutamiento y Movilización"”. Sentencia C-511 de 1994. Disponible en: http://www.corteconstitucional.gov.co/ relatoria/1994/C-511-94.htm [Fecha de consulta 14 de mayo de 2014] p. 23.

- Corte Constitucional. 8 de febrero de 1995. "Proceso de tutela T-45125, interpuesto por Ismael Simijaca y Dulcelina Pineda de Malagón en contra de Elver García Camacho". Sentencia T-036 de 1995. Disponible en http://www.corteconstitucional.gov.co/ relatoria/1995/T-036-95.htm [Fecha de visita 14 de mayo de 2014] p. 7.

- Corte Constitucional. 16 de febrero de 1995. "Demanda de inconstitucionalidad contra la Ley 104 de 1993”. Sentencia C-055 de 1995. Disponible en http://www.corteconstitucional.gov.co/ relatoria/1995/C-055-95.htm [Fecha de consulta 14 de mayo de 2014] p. 70, 81.

- Corte Constitucional. 19 de mayo de 1995. "Revisión constitucional del "Protocolo adicional a los Convenios de Ginebra del 12 de agosto de 1949, relativo a la protección de las víctimas de los conflictos armados sin carácter internacional (Protocolo II)" hecho en Ginebra el 8 de junio de 1977, y de la Ley 171 del 16 de diciembre de 1994, por medio de la cual se aprueba dicho Protocolo". Sentencia C-225 de 1995. Disponible en http://www. corteconstitucional.gov.co/relatoria/1995/C-225-95.htm [Fecha de consulta 14 de mayo de 2014] p. 57, 99-102.

- Corte Constitucional. 6 de julio de 1995. "Demanda de inconstitucionalidad contra la Ley 104 de 1993 "por la cual se consagran unos instrumentos para la búsqueda de la convivencia, la eficacia de la justicia y se dictan otras disposiciones"”. Sentencia C-283 de 1995. Disponible en http://www.corteconstitucional.gov. co/relatoria/1995/C-283-95.htm [Fecha de consulta 14 de mayo de 1995] p. 49.

- Corte Constitucional. 29 de junio de 1995. "Demanda de inconstitucionalidad contra la Ley 104 de 1993 "por la cual se consagran unos instrumentos para la búsqueda de la convivencia, la eficacia de la justicia y se dictan otras disposiciones"”. Sentencia C-283 de 1995. Disponible en: http://www.corteconstitucional.gov. co/relatoria/1995/C-283-95.htm [Fecha de consulta 14 de mayo de 2014] p. 54. 
- Corte Constitucional. 8 de febrero de 1996. "Revisión constitucional del Decreto 1902 del 2 de noviembre de 1995, "Por el cual se toman medidas en materia de información y se dictan otras disposiciones"”. Sentencia C-045, 1996. Disponible en http://www. corteconstitucional.gov.co/relatoria/1996/C-045-96.htm [Fecha de visita 14 de mayo de 2014] p. 19.

- Corte Constitucional. 19 de febrero de 1996. "Proceso de tutela número T- 84047 promovido por María Elvia Benavides de Chávez contra Luis Idelfonso Chávez". Sentencia T-602, 1996. Disponible en: http://www.corteconstitucional.gov.co/relatoria/1996/T-062-96. htm [Fecha de consulta 14 de mayo de 2014] p. 9.

- Corte Constitucional. 7 de noviembre de 1997. "Demanda de inconstitucionalidad contra los artículos $4^{\circ}$ (parcial), 23, 24, 25, 26, 27, 28, 29, 39, 40, 41, 42, 43, 44, 45 y 46 del Decreto 356 del 11 de febrero de 1994, "Por el cual se expide el Estatuto de Vigilancia y Seguridad Privada"”. Sentencia C-572 de 1997. Disponible en http://www.corteconstitucional.gov.co/relatoria/1997/C-572-97.htm [Fecha de visita 14 de mayo de 2014] p. 51.

- Corte Constitucional. 25 de mayo de 1995. "Amparo del derecho al medio ambiente libre de ruido, y su concurrencia con otros derechos como la tranquilidad y la salud". Sentencia T-226 de 1995. Disponible en http://www.corteconstitucional.gov.co/ relatoria/1995/T-226-95.htm [Fecha de consulta 14 de mayo de $2014]$ p. 7.

- Corte Constitucional. 17 de abril de 1997. "Acciones de tutela instauradas por Yaneth Rubiano Labro y otros, en representación de sus hijos, soldados bachilleres, contra los comandantes del Ejército Nacional y de la Segunda Brigada, y contra el Teniente Coronel José Elías Mahecha Cárdenas". Sentencia SU-200 de 1997. Disponible en: http://www.corteconstitucional.gov.co/relatoria/1997/SU200-97. htm [Fecha de consulta 14 de mayo de 2014] p. 13.

- Corte Constitucional. 23 de septiembre de 1997. "Demanda de inconstitucionalidad contra el artículo 127 del decreto 100 de 1980 "Por medio del cual se expide el Código Penal"”. Sentencia C-456 de 1997. Disponible en http://www.corteconstitucional.gov. co/relatoria/1997/C-456-97.htm [Fecha de consulta 14 de mayo de 2014] p. 39.

- Corte Constitucional. 8 de julio de 1998. "Demanda de inconstitucionalidad contra el artículo 10 , el parágrafo $1^{\circ}$ del artículo 14 y el parágrafo del artículo 20 de la Ley 48 de 1993”. Sentencia C-339 de 1998. Disponible en http://www. corteconstitucional.gov.co/relatoria/1998/C-339-98.htm [Fecha de consulta 14 de mayo de 2014 ]. 
- Corte Constitucional. 8 de julio de 1998. "Acción pública de inconstitucionalidad ejercida por María Teresa Garcés Lloreda contra parte del artículo 13 de la Ley 418 de 1997”. Sentencia C-340 de 1998. Disponible en http://www.corteconstitucional.gov.co/ relatoria/1998/C-340-98.htm [Fecha de consulta 14 de mayo de 2014].

- Corte Constitucional. 10 de agosto de 1998. "Revisión constitucional de la "Convención de Viena sobre el Derecho de los Tratados entre Estados y Organizaciones Internacionales o entre Organizaciones Internacionales", hecha en Viena el 21 de marzo de 1986" y de la Ley No 406 del 24 de octubre de 1997 por medio de la cual se aprueba dicha Convención". Sentencia C-400 de 1998. Disponible en http://www.corteconstitucional.gov.co/ relatoria/1998/C-400-98.htm [Fecha de consulta 14 de mayo de 2014] p. 83.

- Corte Constitucional. 22 de marzo de 2000. "Revisión de la Ley 525 de 1999 "Por medio de la cual se aprueba la "Convención sobre la prohibición del desarrollo, la producción, el almacenamiento y el empleo de armas químicas y sobre su destrucción”, hecho en París el trece (13) de enero de mil novecientos noventa y tres (1993)"'. Sentencia C-328 de 2000. Disponible en http://www. corteconstitucional.gov.co/relatoria/2000/C-328-00.htm [Fecha de visita 14 de mayo de 2014] p. 18, 19.

- Corte Constitucional. 2 de agosto de 2000. "Revisión constitucional de la Ley 554 del 14 de enero de 2000 "Por medio de la cual se aprueba la "Convención sobre la prohibición del empleo, almacenamiento, producción y transferencia de minas antipersonal y sobre su destrucción", hecha en Oslo el dieciocho (18) de septiembre de mil novecientos noventa y siete (1997)"'”. Sentencia C-991 de 2000. Disponible en http:// www.corteconstitucional.gov.co/relatoria/2000/C-991-00.htm [Fecha de visita 14 de mayo de 2014] p. 43.

- Corte Constitucional. 24 de enero de 2001. "Demanda de inconstitucionalidad contra el artículo 8 (parcial) de la Ley 418 de 1997". Sentencia C-048 de 2001. Disponible en http://www. corteconstitucional.gov.co/relatoria/2001/C-048-01.htm [Fecha de consulta 14 de mayo de 2014] [Fecha de consulta 14 de mayo de 2014] p. 25, 27, 28.

- Corte Constitucional. 9 de agosto de 2001. "Demanda de inconstitucionalidad contra el artículo $4^{\circ}$ de la ley 169 de 1.896". Sentencia C-836 de 2001. Disponible en http://www. corteconstitucional.gov.co/relatoria/2001/C-836-01.htm [Fecha de visita 14 de mayo de 2014] p. 19-38

- Corte Constitucional. 3 de abril de 2002. "Demanda de inconstitucionalidad contra el artículo 137 de la Ley 600 de 2000 "(p)or la cual se expide el Código de Procedimiento 
Penal"”. Sentencia C-228 de 2002. Disponible en: http://www. corteconstitucional.gov.co/relatoria/2002/C-228-02.htm [Fecha de consulta 14 de mayo de 2014] p. 32

- Corte Constitucional. 9 de abril de 2002. "Demanda de inconstitucionalidad contra el numeral 6 del artículo 6 de la Ley 25 de 1992". Sentencia C-246 de 2002. Disponible en: http://www. corteconstitucional.gov.co/relatoria/2002/C-246-02.htm [Fecha de consulta 14 de mayo de 2014] p. 10.

- Corte Constitucional. 30 de julio de 2002. "Revisión de la Ley 742 del 5 de junio de 2002 "Por medio de la cual se aprueba el Estatuto de Roma de la Corte Penal Internacional, hecho en Roma el día diecisiete (17) de julio de mil novecientos noventa y ocho (1998)"'”. Sentencia C-578 de 2002. Disponible en http:// www.corteconstitucional.gov.co/relatoria/2002/C-578-02.htm [Fecha de visita 14 de mayo de 2014] p. 102

- Corte Constitucional 28 de agosto de 2002. "Demanda de inconstitucionalidad contra el artículo 13 de la Ley 733 de 2002". Sentencia C-695 de 2002. Disponible en http://www. corteconstitucional.gov.co/relatoria/2002/C-695-02.htm [Fecha de visita 14 de mayo de 2014] p. 54.

- Corte Constitucional. 30 de julio de 2002. "Revisión de la Ley 742 del 5 de junio de 2002 "Por medio de la cual se aprueba el Estatuto de Roma de la Corte Penal Internacional, hecho en Roma el día diecisiete (17) de julio de mil novecientos noventa y ocho (1998"”. Sentencia C-578 de 2002. Disponible en http://www. corteconstitucional.gov.co/relatoria/2002/C-578-02.htm [Fecha de consulta14 de mayo de 2014] p. 74.

- Corte Constitucional. 21 de marzo de 2003. "Acción de tutela instaurada por Javier Giraldo Moreno en contra del Fiscal General de la Nación". Sentencia T-249 de 2003. Disponible en http://www. corteconstitucional.gov.co/relatoria/2003/T-249-03.htm [Fecha de consulta 14 de mayo de 2014] p. 22, 26.

- Corte Constitucional. 8 de julio de 2004. "Revisión constitucional de la Ley 846 de noviembre 6 de 2003, "por medio de la cual se aprueba el 'Protocolo Adicional al Acuerdo de Cartagena', 'Compromiso de la Comunidad Andina por la Democracia', hecho en Oporto, Portugal, el diecisiete (17) de octubre de mil novecientos noventa y ocho (1998)"”. Sentencia C-644 de 2004. Disponible en http://www.corteconstitucional.gov.co/relatoria/2004/C-644-04.htm [Fecha de consulta 14 de mayo de 2014] p. 50.

- Corte Constitucional. 28 de junio de 2005. "Proceso de revisión del fallo de tutela proferido por la Sala de Casación Penal de la Corte Suprema de Justicia, en relación con la acción tutelar impetrada por la Asociación para la Promoción Social Alternativa Minga, 
contra el Fiscal Delegado de la Unidad de los Derechos Humanos de la Fiscalía General de la Nación y el Fiscal 42 Delegado ante el Tribunal Superior de Bogotá”. Sentencia T-589 de 2005. Disponible en http://www.corteconstitucional.gov.co/relatoria/2005/T-589-05. htm [Fecha de consulta 14 de mayo de 2014] p. 38-39.

- Corte Constitucional. 6 de septiembre de 2005. "Demanda de inconstitucionalidad contra el Art. 19 (parcial) de la Ley 782 de 2002". Sentencia C-928 de 2005. Disponible en http://www. corteconstitucional.gov.co/relatoria/2005/C-928-05.htm [Fecha de consulta 14 de mayo de 2014] p. 17, 18.

- Corte Constitucional. 16 de mayo de 2006. "Demanda de inconstitucionalidad contra los artículos $1^{\circ}$, parcial; $2^{\circ}$, parcial; 12, parcial; 22, parcial; 26, parcial; 31, parcial y 80 , parcial de la ley 916 de 2004, "Por la cual se establece el reglamento nacional taurino'”. Sentencia C-367 de 2006. Disponible en http://www. corteconstitucional.gov.co/relatoria/2006/C-367-06.htm [Fecha de visita 14 de mayo de 2014] p. 27.

- Corte Constitucional. 18 de mayo de 2006. "Demanda de inconstitucionalidad contra los artículos 2, 3, 5, 9, 10, 11.5, 13, 16, $17,18,19,20,21,22,23,24,25,26,27,28,31,34,37$ numerales 5 y 7, 46, 47, 48, 54, 55, 58, 62, 69, 70 y 71 de la Ley 975 de 2005 "Por la cual se dictan disposiciones para la reincorporación de miembros de grupos armados organizados al margen de la ley, que contribuyan de manera efectiva a la consecución de la paz nacional y se dictan otras disposiciones para acuerdos humanitarios", y contra la ley en su integridad". Sentencia C-370 de 2006. Disponible e http://www. corteconstitucional.gov.co/relatoria/2006/C-370-06.htm [Fecha de visita 14 de mayo de 2014] p. 235, 236, 239, 285, 299.

- Corte Constitucional. 3 de diciembre de 2007. "Acción de tutela instaurada por Javier Giraldo Moreno contra el Ministerio de Defensa Nacional". Sentencia T-1025 de 2007. Disponible en Disponible en http://www.corteconstitucional.gov. co/relatoria/2007/T-1025-07.htm [Fecha de visita 14 de mayo de 2014].

- Corte Constitucional. 24 de agosto de 2011. "Demanda de inconstitucionalidad contra el artículo 10 (parcial) de la Ley 1437 de 2011 "por la cual se expide el Código de Procedimiento Administrativo y de lo Contencioso Administrativo". Sentencia C-634 de 2011. Disponible en http://www.corteconstitucional.gov.co/relatoria/2011/C-634-11.htm [Fecha de visita 14 de mayo de 2014] pp. 28-43

- Corte Constitucional. 1 de noviembre de 2011. "Demanda de inconstitucionalidad: del artículo 102 (parcial) de la Ley 1437 de 2011, por la cual se expide el Código de Procedimiento Administrativo y de lo Contencioso Administrativo". Sentencia C-816 
de 2011. Disponible en http://www.corteconstitucional.gov.co/ relatoria/2011/C-816-11.htm [Fecha de visita 14 de mayo de 2014] pp. 29-35.

- Corte Constitucional. 26 de marzo de 2012. "Acción de Tutela instaurada por Alba Luz Marrugo Mestra, Neiver Alexander Gordón Romero y Héctor Eliécer Cumplido Barbudo contra la Alcaldía Distrital de Cartagena de Indias -Secretaría de Infraestructura-, el Consorcio Cartagena 2010 y Transcaribe". Sentencia T-244 de 2012. Disponible en: http://www.corteconstitucional.gov.co/ relatoria/2012/T-244-12.htm [Fecha de consulta 14 de mayo de 2014] p. 26.

- Corte Constitucional. 9 de mayo de 2012. "Demanda de inconstitucionalidad contra los incisos $1^{\circ}$ y $3^{\circ}$ del artículo 67 de la Ley 975 de 2005 "por la cual se dicta disposiciones para la reincorporación de miembros de grupos armados organizados al margen de la ley, que contribuyan de manera efectiva a la consecución de la paz nacional y se dictan otras disposiciones para acuerdos humanitarios"”. Sentencia C-333 de 2012. Disponible en http:// www.corteconstitucional.gov.co/relatoria/2012/C-333-12.htm [Fecha de visita 14 de mayo de 2014] p. 20.

- Corte Constitucional. 25 de julio de 2012. "Demanda de inconstitucionalidad: de los artículos 102 (parcial), 269 (parcial) y 270 (parcial) de la ley 1437 de 2010 "Por la cual se expide el Código de Procedimiento Administrativo y de lo Contencioso Administrativo del artículo 102 (parcial) de la Ley 1437 de 2010, por la cual se expide el Código de Procedimiento Administrativo y de lo Contencioso Administrativo"'. Sentencia C-588 de 2012. Disponible en http:// www.corteconstitucional.gov.co/relatoria/2012/C-588-12.htm [Fecha de visita 14 de mayo de 2014] pp. 7-20.

- Corte Constitucional. 28 de agosto de 2013. "Demanda de inconstitucionalidad contra el artículo $1^{\circ}$ del Acto Legislativo 01 de 2012 (parcial)". Sentencia C-579 de 2013. Disponible en http:// www.corteconstitucional.gov.co/relatoria/2013/C-579-13.htm [Fecha de consulta 14 de mayo de 2014] p. 146.

\section{NORMATIVA}

- Carta constitutiva de la Organización de Estados Americanos, Tomado de www.oas.org/juridico/spanish/tratados/a-41.html capturado 3173/2014.

- Carta de las Naciones Unidas. Disponible en http://www.un.org/es/ documents/charter/chapter5.shtml consultada 3/10/2013.

- Constitución Política de 1991, Colombia. 
- Convención sobre la Imprescriptibilidad de los Crímenes de Guerra y de los Crímenes de Lesa Humanidad. Tomado de http://www. tc.gob.pe/tratados/uni_ddhh/instru_alca_especifi_uni/instru_ crimenes_guerra/lesa_humani.pdf consultado el 3/10/2013.

- Declaración Universal de Derechos Humanos. Tomado de https:// www.un.org/es/documents/udhr/k Capturado 31/3/2014.

- Decreto Ley 2591 de 1991, "Por el cual se reglamenta la acción de tutela consagrada en el artículo 86 de la Constitución Política". Disponible en www.corteconstitucional.gov.co/lacorte/ DECRETO\%202591.php

- Estatuto del Tribunal Militar Internacional de Nuremberg de 1945. Disponible en http://www.cruzroja.es/dih/pdf/estatuto_del_ tribunal_militar_internacional_de_nuremberg.pdf consultada el $3 / 10 / 2013$.

- Ley 472 de 1998, Colombia, "por la cual se desarrolla el artículo 88 de la Constitución Politica de Colombia en relación con el ejercicio de las acciones populares y de grupo y se dictan otras disposiciones". Disponible en www.alcaldiabogota.gov.co/sisjur/normas/Norma1. jsp? $\mathrm{i}=188$

- Ley 1482 de 2011, Colombia, "Por medio de la cual se modifica el Código Penal y se establecen otras disposiciones". Disponible en: www.bibliotecajuridica.com.co/LEY_1482_DE_2011.pdf

\section{OTRAS FUENTES}

- Diccionario de la Real Academia Española de la Lengua. Tomado de http://www.rae.es/rae.html Consulta 3/10/2013 